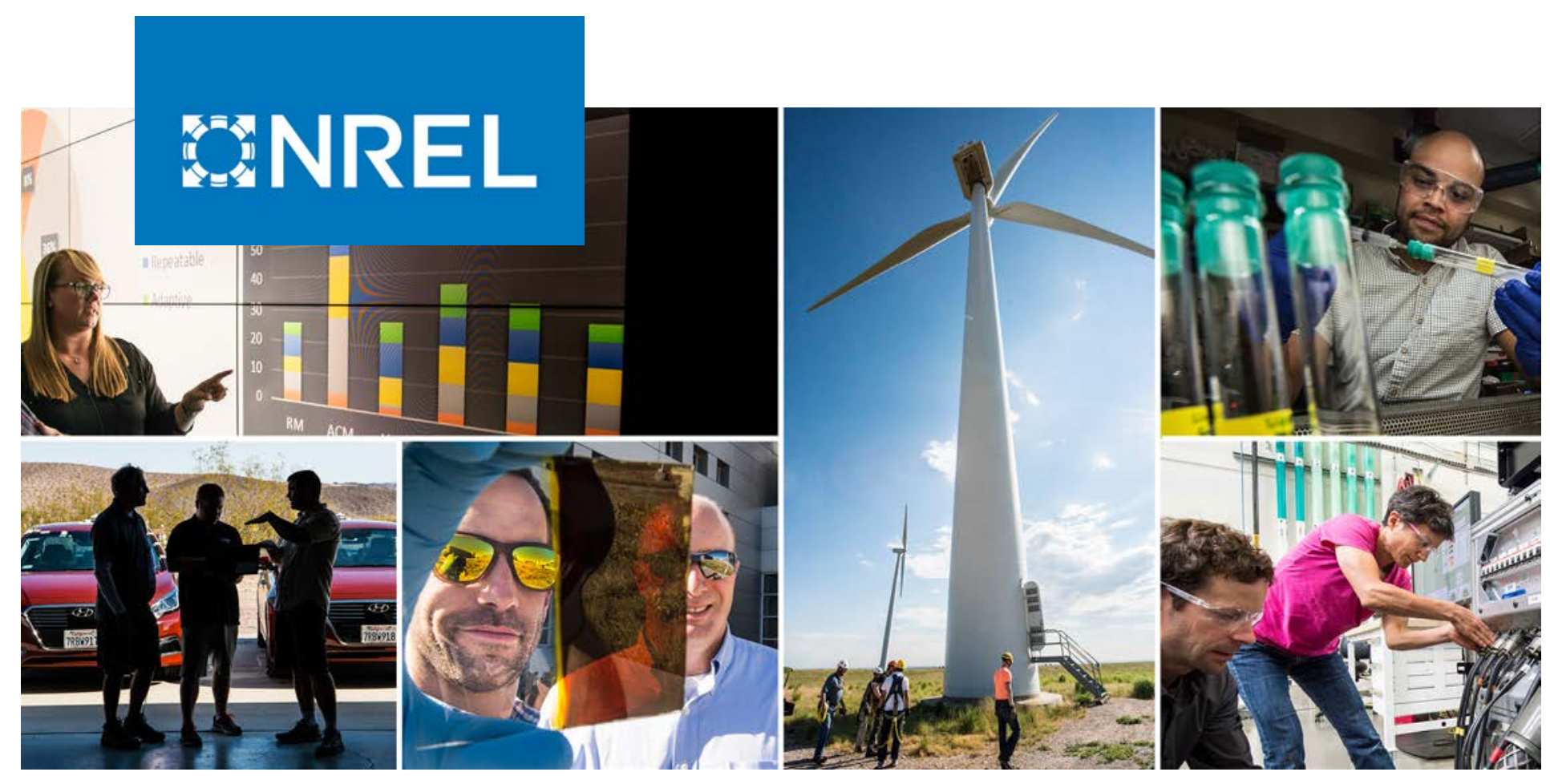

\title{
Algal Biomass Conversion to Fuels via Combined Algae Processing (CAP): 2019 State of Technology and Future Research
}

Ryan Davis and Matthew Wiatrowski

NREL is a national laboratory of the U.S. Department of Energy Office of Energy Efficiency \& Renewable Energy

Operated by the Alliance for Sustainable Energy, LLC

This report is available at no cost from the National Renewable Energy Laboratory (NREL) at www.nrel.gov/publications.
Technical Report

NREL/TP-5100-76568

April 2020 


\title{
ENREL
}

\section{Algal Biomass Conversion to Fuels via Combined Algae Processing (CAP): 2019 State of Technology and Future Research}

\author{
Ryan Davis and Matthew Wiatrowski
}

\section{Suggested Citation}

Davis, Ryan, and Matthew Wiatrowski. 2020. Algal Biomass Conversion to Fuels via Combined Algae Processing (CAP): 2019 State of Technology and Future Research. Golden, CO: National Renewable Energy Laboratory. NREL/TP-5100-76568.

https://www.nrel.gov/docs/fy20osti/76568.pdf.

NREL is a national laboratory of the U.S. Department of Energy Office of Energy Efficiency \& Renewable Energy Operated by the Alliance for Sustainable Energy, LLC

This report is available at no cost from the National Renewable Energy Laboratory (NREL) at www.nrel.gov/publications.

Contract No. DE-AC36-08GO28308
Technical Report NREL/TP-5100-76568 April 2020

National Renewable Energy Laboratory 15013 Denver West Parkway Golden, CO 80401 303-275-3000 • www.nrel.gov 


\section{NOTICE}

This work was authored by the National Renewable Energy Laboratory, operated by Alliance for Sustainable Energy, LLC, for the U.S. Department of Energy (DOE) under Contract No. DE-AC36-08GO28308. Funding provided by U.S. Department of Energy Office of Energy Efficiency and Renewable Energy Bioenergy Technologies Office. The views expressed herein do not necessarily represent the views of the DOE or the U.S. Government.

This report is available at no cost from the National Renewable Energy Laboratory (NREL) at www.nrel.gov/publications.

U.S. Department of Energy (DOE) reports produced after 1991 and a growing number of pre-1991 documents are available free via www.OSTI.gov.

Cover Photos by Dennis Schroeder: (clockwise, left to right) NREL 51934, NREL 45897, NREL 42160, NREL 45891, NREL 48097, NREL 46526.

NREL prints on paper that contains recycled content. 


\section{Acknowledgements}

The authors wish to thank the following researchers for their contributions to this work: Lieve Laurens, Phil Pienkos, Eric Knoshaug, Tao Dong, Jake Kruger, Nick Nagle, Yat-Chen Chou, Christopher Kinchin, Bruno Klein, and Zia Abdullah from the National Renewable Energy Laboratory (NREL); Lynn Wendt, Brad Wahlen from Idaho National Laboratory (INL); and other partners in the Rewiring Algal Carbon Energetics for Renewables (RACER) (BETO grant) project. This report provides a high-level overview of research data across key unit operations as utilized in updating NREL's State of Technology (SOT) benchmark models, based on inputs furnished from those researchers; however, it is not intended to present an exhaustive summary of all research activities, methods, or data outputs, and we defer to those and others' research works for further context. 


\section{List of Acronyms}

$\mathrm{AD}$

AFDW

ASU

AzCATI

BDO

BETO

CA

CAP

CUBI

DISCOVR

FA

FAME

FFA

FY

GGE

HCSD

HLSD

HDO

$\mathrm{HI}$

INL

MBSP

MFSP

MOT

NIPU

NREL

PU

PUFA

SLS

SOT

TEA

USFA anaerobic digestion

ash free dry weight

Arizona State University

Arizona Center for Algae Technology and Innovation

2,3-butanediol

Bioenergy Technologies Office

carboxylic acids

Combined Algae Processing

catalytic upgrading of biochemical intermediates (under ChemCatBio

Consortium)

Development of Integrated Screening, Cultivar Optimization, and

Verification Research

Florida Algae (testbed site under ATP ${ }^{3}$ Consortium)

fatty acid methyl ester

free fatty acid

fiscal year

gallon gasoline equivalent

High-carbohydrate Scenedesmus

High-lipid Scenedesmus

hydrodeoxygenation

hydroisomerization

Idaho National Laboratory

minimum biomass selling price

minimum fuel selling price

mild oxidative treatment

non-isocyanate polyurethane

National Renewable Energy Laboratory

polyurethane

Poly-unsaturated fatty acid

solid-liquid separations

State of Technology

techno-economic analysis

unsaturated fatty acid 


\section{Executive Summary}

The annual State of Technology (SOT) assessment is an essential activity for platform research conducted under the Bioenergy Technologies Office. It allows for the impact of research progress (both directly achieved in-house at NREL and furnished by partner organizations) to be quantified in terms of economic improvements in the overall biofuel production process for a particular biomass processing pathway, whether based on terrestrial or algal biomass feedstocks. As such, initial benchmarks can be established for currently demonstrated performance, and progress can be tracked towards out-year goals to ultimately demonstrate economically viable biofuel technologies.

NREL's algae SOT benchmarking efforts focus both on front-end algal biomass production and separately on back-end conversion to fuels through NREL's "combined algae processing" (CAP) pathway. The production model is based on outdoor long-term cultivation data, enabled by comprehensive algal biomass production trials conducted under Development of Integrated Screening, Cultivar Optimization, and Verification Research (DISCOVR) consortium efforts, driven by data furnished by Arizona State University (ASU) at the Arizona Center for Algae Technology and Innovation (AzCATI) testbed site. The CAP model is based on experimental efforts conducted under NREL research and development projects.

This report focuses on back-end conversion of algal biomass through the CAP pathway, highlighting the 2019 updates to minimum fuel selling price (MFSP). The modeled biomass costs (minimum biomass selling price [MBSP]), yields, and seasonal variability from the upstream cultivation SOT model were incorporated into downstream Aspen Plus CAP models, reflecting experimental data from NREL CAP R\&D activities. Recently NREL CAP experimental efforts have observed more challenging biomass recalcitrance across dilute acid pretreatment for a number of saline strains, resulting in poor pretreatment performance/carbohydrate hydrolysis yields, and thereby confounding CAP conversion pathways focused in part on fermentation of monomeric sugars to fuel intermediates or other products. For this reason, as well as a planned shift in focus towards accommodating a more feedstock-flexible CAP process that may allow for higher-protein compositions in the future, in early 2019 NREL algae research began shifting experimental focus to a new CAP approach that replaces sugarsthrough-fermentation and protein-through-anaerobic digestion with a route for co-converting both constituents to fuel products via a series of catalytic upgrading steps. However, that new processing approach is still in nascent stages of development and optimization, with only preliminary data beginning to become available at the time of this writing, which begins to demonstrate proof-of-concept for the process but not yet under commercially-relevant conditions as would be practical for an integrated biorefinery system. Accordingly, the 2019 CAP SOT update maintains the same conversion process configurations as well as underlying processing parameters across all unit operations as had been demonstrated in the 2018 SOT, thereby strictly reflecting the implications for MFSP reductions attributed to the improved upstream cultivation performance and resultant seasonal biomass flowrates/MBSPs as documented in NREL's algal biomass SOT report.

In summary, the CAP SOT model inputs included values (originally measured in 2018 and prior) of 74\% fermentable sugar release during dilute acid pretreatment, 95\% sugar recoveries across a membrane solids removal step, and $96 \%$ lipid extraction recovery from biomass solids. The 
clarified sugars achieved $92 \%$ conversion of glucose and mannose to carboxylic acids during fermentation over a productivity of $0.3 \mathrm{~g} / \mathrm{L}$-hr yielding $0.41 \mathrm{~g}$ acids $/ \mathrm{g}$ available sugars (based on data from NREL algae platform research), or $74 \%$ and $55 \%$ conversion of glucose and mannose respectively to 2,3-butanediol (BDO) over a 56 hour batch time yielding $0.34 \mathrm{~g} \mathrm{BDO/g}$ sugars (based data from NREL algae research conducted under the Rewiring Algal Carbon Energetics for Renewables [RACER] project grant). Maintaining those same fractional conversions and other operational parameters coupled with the updated 2019 SOT MBSP value of \$764/ton (based on ASU evaporation rates), the 2019 MFSP translates to \$10.53/gallon gasoline equivalent (GGE) and \$10.91/GGE for the acids and BDO fermentation pathways, respectively. Alternatively, the 2019 MBSP value associated with Florida Algae (FA) evaporation rates at $\$ 670 /$ ton ash free dry weight (AFDW) would reduce the MFSP to $\$ 9.50 /$ GGE and $\$ 9.88 / \mathrm{GGE}$ for the acids and BDO cases, respectively.

Relative to an updated back-cast 2018 SOT case, this indicates an improvement of $\$ 2.17$ $\$ 2.20 /$ GGE (roughly $17 \%$ ) for the ASU evaporation case, or $\$ 1.78-\$ 1.82 /$ GGE (roughly $16 \%$ ) for the FA evaporation case, across the acids and BDO pathways respectively. In all cases, the addition of full pond liners in the upstream biomass farm models would increase SOT fuel costs by approximately $\$ 2.14 /$ GGE relative to the above values based on minimally-lined ponds. Additionally, as in prior SOTs these results are all based on an assumed biomass composition consistent with NREL's high-carbohydrate Scenedesmus (HCSD) composition targets.

The resulting total fuel yields were modeled as $91.0 \mathrm{GGE} /$ ton and $91.4 \mathrm{GGE} /$ ton AFDW for the acids and BDO pathways respectively, translating to 2,105 and 2,114 GGE/acre-year when including upstream cultivation productivity and seasonal biomass storage losses (based on wet seasonal storage reflective of HCSD biomass compositions). Finally, this milestone reports on key process sustainability indicators for the CAP conversion stage including mass and carbon yields to fuels and coproducts, freshwater consumption, and facility power balances/natural gas demands. In keeping with recent BETO guidance, formal life cycle assessment sustainability metrics such as greenhouse gas emissions or fossil energy consumption are not calculated here, but will be deferred to Argonne National Laboratory (whom NREL has already sent input/output inventory data to prior to this report writing). 


\section{Table of Contents}

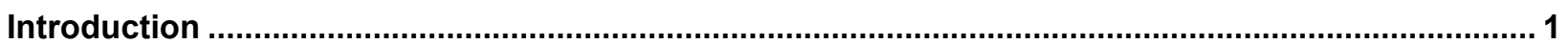

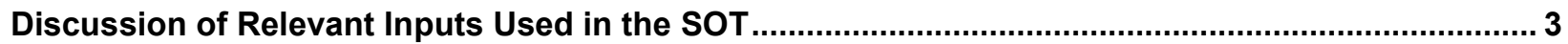

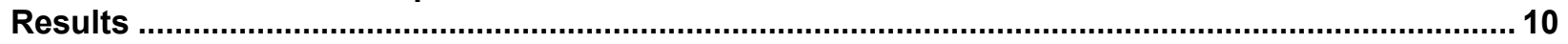

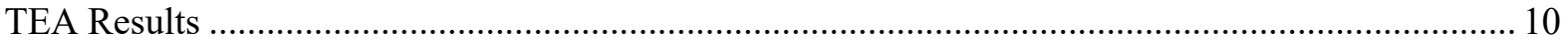

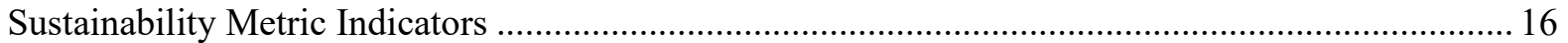

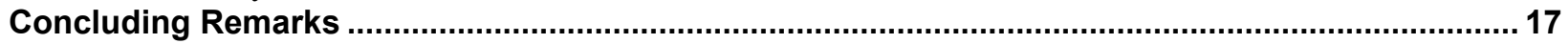

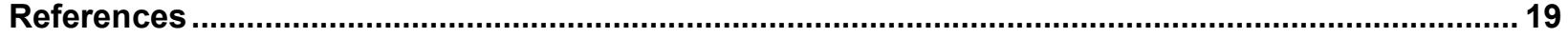




\section{Introduction}

The National Renewable Energy Laboratory (NREL) develops and maintains techno-economic models that simulate the technical and economic aspects of conceptual biorefinery conversion pathways to biofuels and bioproducts, focused on both terrestrial and algal biomass processing routes. For a particular set of process parameters, material and energy balance and flow rate information are generated using Aspen Plus simulation software [1], for a given facility size or biomass throughput rate. These data are used to size and cost process equipment and compute raw material and other operating costs. Using a discounted cash flow rate of return analysis, the minimum fuel selling price (MFSP) or minimum biomass selling price (MBSP) required to obtain a net present value (NPV) of zero for a $10 \%$ internal rate of return (IRR) is determined. The result is a techno-economic model that reasonably estimates an " $n^{\text {th }}$-plant" production cost for this pre-commercial process.

Over recent years, NREL has published a number of design reports for both the production of algal biomass and the conversion of algae to fuels via the "combined algae processing" (CAP) pathway [2,3], both of which focused on out-year targets that, if achieved, would translate to a modeled MBSP of $\$ 494 /$ ton for biomass (2014\$, ash free dry weight [AFDW] basis) and MFSP of \$5.90/GGE for resulting fuels (after revising the original CAP design case to match up with the outputs from the newer algae farm design case). The latter MFSP projection was based on NREL's original CAP processing approach focused on fuels via well-understood conversion technologies for fermenting sugars to ethanol and extracting/upgrading lipids to diesel-range blend stocks, which is evolving towards a focus on hydrocarbon fuels and value-added coproducts to reduce the MFSP towards future targets. However, in order to achieve such fuel cost goals in the future, substantial improvements are required particularly around biomass cultivation costs, representing the largest contributor to overall fuel cost, driven most strongly in turn by the achievable annual cultivation productivity. But even upon achieving future cultivation targets and resultant MBSP goals near \$500/ton, this represents a roughly seven-fold increase over terrestrial biomass cost goals [4]; at even high fuel yield targets of 100 gallons gasoline equivalent (GGE)/ton as can be achieved from algal biomass conversion pathways, this would translate to a minimum MFSP of $\$ 5 / \mathrm{GGE}$ tied to feedstock cost alone. Accordingly, in order to ultimately meet Bioenergy Technologies Office (BETO) targets of \$2.5/GGE by 2030, the inclusion of value-added coproducts will be necessary in order to increase biorefinery revenues and offset feedstock and conversion processing costs to reduce MFSPs [5].

In light of the above importance for non-fuel coproducts to be produced alongside fuels in order to drive down MFSPs in the future, the original CAP pathway as configured to produce ethanol/hydrocarbon fuels alone along with nutrient recycles (initial basis of 2015 experimental SOT) was modified to begin investigating coproduct opportunities, first focused on sugar fermentation to succinic acid (the subject of 2016-2017 experimental SOTs), and then conceptually reflected in further techno-economic analysis (TEA) iterations evaluating economic potential for other products such as surfactants, plastics, and polyols/polyurethanes (not yet included in experimental SOT data) [6]. While prior SOT experimental focus on succinic acid demonstrated proof-of-concept with promising fermentation performance on algal hydrolysates, and eventually a product such as succinic acid would help support achievement of $\$ 2.5 / \mathrm{GGE}$ MFSP goals in the future, at the time during prior SOTs the high SOT biomass costs translated to 
high calculated MFSP benchmarks to the extent that the required selling price of fuel exceeded the value of succinic acid, thus the focus on succinic acid was too early to appreciably help improve SOT benchmark economics. Accordingly, NREL algae experimental work shifted back to fuels for the 2018-2019 SOT periods, but in this case focused on hydrocarbon fuel products via lipid extraction and upgrading as well as algal sugar fermentation to intermediate products that can be subsequently catalytically upgraded to hydrocarbons [7]. That approach followed processing concepts initially established under NREL's Biochemical Platform research for such sugar fermentation/catalytic upgrading pathways (derived from corn stover) [4], subsequently demonstrating promising performance on algal sugars in an integrated process coupled with algal lipid upgrading and anaerobic digestion of protein. This established an initial SOT framework upon which coproducts could be again included in the future, either from sugars, protein, or lipids, with the latter of primary focus most recently to divert a fraction of lipids to polyurethanes as a high-value, high-volume product [5]. The remainder of this report highlights the key experimental performance parameters constituting the 2018-2019 SOT benchmarks for this fuelfocused CAP framework, generally established in 2018 with subsequent 2019 updates reflective of additional upstream cultivation cost improvements.

We emphasize that the present SOT analysis and the resultant MBSP and MFSP values carry some uncertainty related to the assumptions and estimates made for capital and raw material costs. Without a detailed understanding of the underlying basis, the absolute computed selling price has limited relevance. By demonstrating the cost impact of various process parameters individually or in concert, the model helps guide research by indicating where the largest opportunities for cost reduction exist. It is also acknowledged that "State of Technology" is arguably a misnomer since no commercial algal biofuel facility exists today (e.g., growing algal biomass for purposes of producing fuels at commercial scale), and because the SOT performance results documented here are based solely on NREL and partner (DISCOVR) data and do not necessarily represent a broader picture of all performers within and beyond BETO's portfolio. 


\section{Discussion of Relevant Inputs Used in the SOT}

The base case CAP configuration as reflected in NREL's fiscal year 2018 (FY18) SOT update and maintained for the FY19 SOT is shown in Figure 1 [8]. In summary, that process approach utilizes diversion of peak seasonal biomass capacity from upstream cultivation in excess of the annual average feed rate to a wet anaerobic storage process, and pulling from storage during lowproduction seasons below the average (with wet storage performance data furnished by partners at Idaho National Laboratory [INL] [9]). The material is delivered from cultivation after dewatering to $20 \mathrm{wt} \%$ solids AFDW. Following storage as applicable, the biomass is routed to dilute acid pretreatment, traditionally used to hydrolyze carbohydrates to monomeric sugars and to enable effective downstream lipid extraction. The pretreated hydrolysate is processed through solid/liquid separation using a vacuum filter press, with the solids routed to extraction and the liquor routed to sugar fermentation. The basis SOT schematic reflects two fuel fermentation pathways based on similar focus areas under the Biochemical Conversion platform, namely fermentation to carboxylic acid or 2,3-butanediol (BDO) intermediates, in either case subsequently upgrading the given intermediate to final hydrocarbon fuel products through a series of catalytic steps. The solids product from upstream solid/liquid separation is routed to lipid extraction across a series of three mixing/phase separation steps in series, each utilizing a non-polar (hexane or light naphtha) solvent with a polar (ethanol) co-solvent. Both the extract and raffinate phases are routed to distillation columns for recovery and recycle of the respective solvents. The remaining lipid stream is routed to hydrotreating (consisting of a combined hydrodeoxygenation/hydro-isomerization [HDO/HI] step) for production of hydrocarbon fuels. Finally, the raffinate product after ethanol solvent recovery is routed to anaerobic digestion (AD) to produce biogas for heat and power benefits as well as enabling recycle of N/P nutrients back to cultivation.

Beyond experimentally-demonstrated operations constituting historical SOTs to date, both this CAP approach as well as a "new" earlier-conceptual approach (discussed below) envisage modifications moving forward that incorporate diverting a fraction of algal lipids for upgrading to polyols/polyurethanes (PU), as a key enabling factor in order to achieve \$2.5/GGE MFSP goals by 2030 [5], [10]. These future steps are represented as orange boxes in Figure 1. To date, TEA future target studies have assumed a more "standard" approach for PU production based on epoxidation of algal lipids, ring-opening of epoxides to form polyols, and cross-linking of polyols with isocyanates to produce PU foams. This was done primarily to demonstrate proof of concept for valorizing algal lipids as may be upgraded to high-value PU coproducts, based on the best-understood reaction pathway and associated processing costs, yields, and product applications/values. However, recent experimental work has begun investigating a more novel route to PU products that may offer several benefits over the traditional route described above, primarily avoidance of toxic and environmentally deleterious isocyanate cross-linkers [21]. This non-isocyanate polyurethane (NIPU) route maintains the initial epoxidation step, but then rather than epoxide ring opening to polyols, the ring is reacted with $\mathrm{CO}_{2}$ forming a carbonate. These carbonated epoxides may react with diamine cross linkers to form NIPU end-products. This may enable a fully-renewable PU process, given that both the diamines and $\mathrm{CO}_{2}$ could be derived from the algal biomass. While this work has yielded promising results over recent months, the NIPU process has not yet been evaluated through TEA modeling and thus is not yet reflected in the current CAP SOT update; nor is standard isocyanate-based foam PU given that the latter 
route has not been investigated experimentally in order to provide first-hand data from algal lipids. This will be an area of further focus moving forward into future SOT iterations.

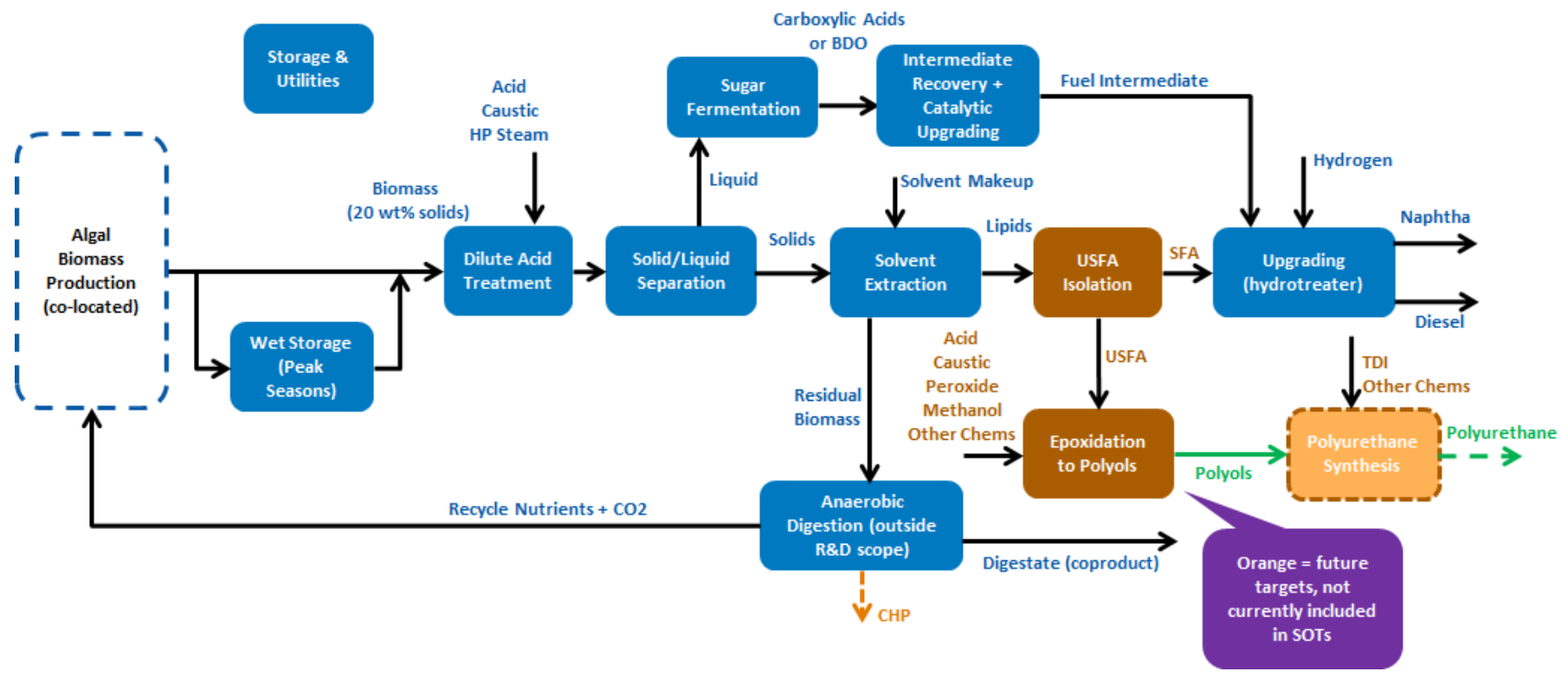

Figure 1: Schematic diagram of basis CAP configuration as reflected in algae harmonization report and FY18-19 SOT [5], [8].

Orange boxes $=$ future goals for inclusion of high-value coproducts (not yet reflected in SOTs).

During early FY19, NREL experimental efforts were conducted with a high-ash, halotolerant algal species to demonstrate conversion through the CAP process depicted in Figure 1 for saltwater algae (Scenedesmus IITRIND2) [11]. Although prior work had been conducted on nonfreshwater algae species of various salinities with good results, this particular IITRIND2 species was seen to exhibit high recalcitrance with low carbohydrate hydrolysis across pretreatment, generally below $20 \%$ monomeric sugar yield across a range of temperatures and acid loadings. This was hypothesized to be due to elevated protein and ash, rendering the biomass more resistant to acid pretreatment likely with ash incurring a buffering effect to neutralize the acid, as well as such recalcitrance having been observed in other (but not all) saline strains suggesting a strain-dependent effect. In light of such low sugar yields, the researchers opted not to pursue further downstream fermentation on this material given that it would not have led to an improvement over previous SOT results (historically based on $74 \%$ pretreatment sugar yields demonstrated previously). Rather, the experimental work pivoted to a new CAP approach that had begun to be investigated as a means to bypass the dependence on acid pretreatment and high sugar yields for fermentation, while making use of both carbohydrates and protein (soluble or insoluble), and thereby also potentially relaxing the dependence on biomass composition that had historically been affiliated with the CAP pathway.

Briefly, the envisioned process for such an alternative CAP approach is summarized as follows [10], [12]: following diversion of dewatered biomass to wet seasonal storage as necessary (noted above), the biomass would undergo rapid flash hydrolysis pretreatment to maintain good lipid extraction, albeit without requiring high monomeric sugar yields and thus negating dilute acid pretreatment. The whole slurry may then be routed to lipid extraction following a similar 
extraction and lipid upgrading sequence as before. The raffinate (containing both carbohydrates and protein) would then be processed through mild oxidative treatment (MOT), employing an oxidant (i.e., oxygen) at moderate temperature and pressure to convert carbohydrates and protein into carboxylic acids. The MOT product, primarily a mixture of mono- and di-carboxylic acids, may be routed to filtration and ion exchange, capturing liberated $\mathrm{N}$ and $\mathrm{P}$ components for recycle to cultivation, followed by catalytic upgrading through ketonization (forming ketones), condensation (forming oxygenated longer-chain molecules), and HDO (forming finished hydrocarbon fuel components). While this approach possesses the potential for enabling high fuel yields and if desired, simultaneous co-production of polyols/polyurethanes [10], some new steps are still in early stages of conceptual development and more remains to be understood moving forward. Namely, preliminary efforts on MOT upgrading have highlighted an important link between MOT yields and oxygen access to the substrate, with favorable yields initially observed under significantly more dilute substrate conditions of $2 \mathrm{~g} / \mathrm{L}(0.2 \mathrm{wt} \%)$ solids to MOT [12], though more recently improving to $20 \mathrm{~g} / \mathrm{L}$ ( $2 \mathrm{wt} \%$ solids). Either of those concentration levels $(0.2-2 \mathrm{wt} \%$ solids) are not yet practical for an integrated commercial process (ideally in the 15-20\% range) given both significant throughput volumes requiring very large reactor sizes as well as significant heating demands to raise the feed temperature to reactor conditions. Moreover, the resultant concentrations and species of acid products from MOT translated into new product species that had not been initially expected from ketonization and condensation, with preliminary data established for those operations to date based on mock acid substrates.

For the above reasons, the new CAP processing configuration approach described above is still deemed to be too premature and not yet optimized for commercial practicality to be ready for use as a formal FY19 SOT benchmark. Moving forward, there are numerous opportunities to investigate increasing MOT concentrations while maintaining high yields, including different reactor configurations, different combinations of oxygen feed ratios/gas purity and reactor pressures (i.e. pure oxygen at lower oxygen partial pressures, air at higher pressures, or oxygenenriched air in between), or use of a different oxidant such as peroxide which may alleviate gas dispersion challenges at higher solids concentrations. Additionally, further experimental work will be conducted across ketonization, condensation, and HDO to further quantify product species and elemental balances across each step based on an integrated process starting with the basis MOT feed substrate. In the meantime, the present SOT exercise maintains the basis CAP configuration as reflected in the FY18 SOT, as well as all underlying conditions and fractional conversions across each step - summarized in Table 1.

Both sugar fermentation pathways under the FY18 CAP configurations are reflected here. While no notable efforts or improvements were made to either case under FY19 Algae Platform activities for reasons discussed above, ongoing work under the Biochemical Conversion Platform has demonstrated continued improvements for both fermentation pathways during FY19 [13]. Namely, the carboxylic acid pathway has demonstrated over $95 \%$ conversion of glucose to product with minimal diversion of sugars to acetic acid (1:50 ratio of acetic vs butyric acid production) and a doubling of productivity from 0.3 to $0.6 \mathrm{~g} / \mathrm{L}-\mathrm{hr}$ using Clostridium tyrobutyricum, also based on a physically integrated fermentation-pertraction setup with in-situ removal of acids at a $98.4 \%$ recovery rate of butyric acid. The BDO pathway has also demonstrated nearly $100 \%$ utilization of glucose with $90 \%$ overall theoretical yield to BDO within 48 hours (roughly 30\% improvement over FY18 productivity) and minimal acetoin byproduct, using an engineered strain of Zymomonas mobilis. Downstream steps under 
ChemCatBio (catalytic upgrading of biochemical intermediates [CUBI])-supported efforts also demonstrated nearly $100 \%$ conversion for all catalytic upgrading steps within the scope of experimental work (excepting ketone condensation for the acids pathway, demonstrated at $40 \%$ per-pass conversion or $92 \%$ overall net conversion of ketones to condensation products). In all, assuming similar performance levels could also be achieved here under the algae CAP process (likely to be possible barring any differences with mannose which is present for algae but not for corn stover as utilized in the biochemical platform; although work under the Rewiring Algal Carbon Energetics for Renewables (RACER) project has resulted in an engineered Zymomonas strain capable of utilizing mannose on-par with glucose), this would largely support achievement of final future performance targets for all fermentation and catalytic upgrading steps, with lipid extraction also having already exceeded final targets, leaving only pretreatment for future improvement in the prior CAP approaches (as well as subsequent introduction of high-value coproducts). 
Table 1. Process Conditions and Conversions Observed from Experimental CAP Data, Utilized for FY18 SOT [14-17] (maintained consistently for FY19 SOT). Italicized lines represent modeling assumptions, outside experimental scope.

\begin{tabular}{|c|c|c|c|}
\hline \multirow[t]{5}{*}{ Pretreatment } & \multicolumn{2}{|c|}{ Value } & Experimental Notes \\
\hline & \multirow{9}{*}{\multicolumn{2}{|c|}{$\begin{array}{c}20 \%^{\text {a }} \\
2 \% \\
74 \% \\
1.5 \% \\
\text { Yes (vacuum belt filter } \\
\text { with flocculent) } \\
5 \% \\
0.5 \% \\
10 \\
30\end{array}$}} & \multirow{9}{*}{$\begin{array}{l}\text { Pretreatment data } \\
\text { originally based on High- } \\
\text { lipid Scenedesmus } \\
\text { experiments averaged } \\
\text { across eight runs, } \\
\text { extrapolated same } \\
\text { conversions to HCSD } \\
\text { SLS vacuum membrane } \\
\text { based on FY17 data }\end{array}$} \\
\hline & & & \\
\hline & & & \\
\hline & & & \\
\hline Hydrolysate solid-liquid separation & & & \\
\hline Sugar loss & & & \\
\hline Lipid loss & & & \\
\hline SLS flocculent loading (g/kg IS) & & & \\
\hline SLS membrane capacity (kg IS/m²-h) & & & \\
\hline Sugar Fermentation & \multicolumn{2}{|r|}{ BDO } & \multirow{11}{*}{$\begin{array}{l}\text { - Acids data based on } \\
\text { NREL algae platform } \\
\text { R\&D in FY18; BDO data } \\
\text { based on inputs from } \\
\text { NREL researchers under } \\
\text { FY18 RACER project } \\
\text { fermentation work on } \\
\text { Desmodesmus C046 }\end{array}$} \\
\hline Fermentation productivity (g/L-hr) & 0.3 & 56 hour batch & \\
\hline Sugar diversion to organism seed growth & $10 \% b$ & $10 \% b$ & \\
\hline Glucose utilization to product & $92 \%$ c & $74 \%$ c & \\
\hline Mannose utilization to product & $92 \% c$ & $55 \%{ }^{c}$ & \\
\hline Glycerol utilization to product & $92 \% c$ & $0 \% c$ & \\
\hline Butyric acid yield ( $\mathrm{g} / \mathrm{g}$ total available sugars) & 0.41 & NA & \\
\hline Acetic acid yield (g/g total available sugars) & 0.10 & NA & \\
\hline BDO yield ( $\mathrm{g} / \mathrm{g}$ total available sugars) & NA & 0.34 & \\
\hline Acetoin yield (g/g total available sugars) & NA & 0.10 & \\
\hline $\begin{array}{l}\text { Catalytic upgrading: overall yield to HDO feed } \\
\text { (wt\% vs recovered fermentation intermediate) }\end{array}$ & $53 \%$ & $60 \%$ & \\
\hline \multicolumn{4}{|l|}{ Lipid Extraction + Upgrading } \\
\hline Extraction configuration & \multirow{8}{*}{\multicolumn{2}{|c|}{$\begin{array}{c}\text { 3-stage CSTR + } \\
\text { centrifugation with } 2 \\
\text { solvents } \\
2.7: 1.1: 1 \mathrm{~g} / \mathrm{g} / \mathrm{g} \\
15 \\
74 \%-65.4 \%-55.6 \% \\
95.7 \% \\
<11.5 \% \\
707^{\circ} \mathrm{F}, 435 \mathrm{psig}, \sim 5,900 \\
\text { scf/bbl } \mathrm{H}_{2} \text { feed ratio } \\
1 \% \mathrm{Pt} / \mathrm{SAPO}-11, \\
\text { WHSV }=1 \mathrm{hr}^{-1}\end{array}$}} & \multirow{11}{*}{$\begin{array}{l}\text { Extraction yields based } \\
\text { on HCSD biomass, FY18 } \\
\text { data with light naphtha } \\
\text { solvent } \\
\text { - Hydrotreating (HDO+HI) } \\
\text { yields based on HCSD- } \\
\text { extracted lipids, } \\
\text { maintaining FY17 data for } \\
\text { one-step HDO + HI } \\
\text { upgrading }\end{array}$} \\
\hline Solvent loading (nonpolar: EtOH: dry biomas & & & \\
\hline CSTR extraction residence time ( $\mathrm{min}$ ) & & & \\
\hline Convertible lipid extraction yield per step & & & \\
\hline Total convertible lipid extraction yield & & & \\
\hline Non-sterol lipid impurity partition to & & & \\
\hline Hydrotreating conditions & & & \\
\hline Catalyst details & & & \\
\hline $\begin{array}{l}\text { Hydrotreating renewable diesel blend-stock yield } \\
\text { (wt \% of oil feed) } \mathrm{e}\end{array}$ & \multicolumn{2}{|r|}{$63.4 \%$} & \\
\hline Hydrotreating Naphtha yield (wt $\%$ of oil feed) e & \multirow{2}{*}{\multicolumn{2}{|c|}{$\begin{array}{l}21.0 \%^{f} \\
2.55 \% g\end{array}$}} & \\
\hline Hydrotreating $\mathrm{H}_{2}$ Consumption (wt $\%$ of oil feed) & & & \\
\hline
\end{tabular}

a Experimental work based on $25 \%$ solids, adjusted here to $20 \%$ solids for consistency with previously published modeling framework; pretreatment performance is expected to remain unchanged at this value (unpublished data)

b Values were not determined here as part of the scope of experimental work; set consistent with previously documented models [2]

${ }^{\mathrm{C}}$ Does not include sugar diversions to biomass seed growth assumed in the model

d Catalytic upgrading of fermentation intermediates to final hydrocarbon fuels is outside R\&D scope; set consistently with 2017 Algae Harmonization Report for acids case [5], and Biochemical Platform FY18 SOT data for BDO case. Value represents upgrading yields to the final fuel finishing (hydrotreating) reactor feed.

e Hydrotreating yields are based on adjusting original experimental data [15] to achieve $100 \%$ mass closure, based on lipid hydrotreating alone (not including co-processed BDO/acids intermediate products)

${ }^{f}$ Includes light gas correction, estimated separately via mass and element closure to $100 \%$; based on lipids alone ${ }^{9} \mathrm{H}_{2}$ consumption set in model to close elemental $\mathrm{H}$ balance; experimental $\mathrm{H}_{2}$ consumption measured was lower; based on lipids alone 
With the CAP process configuration and performance parameters maintained consistently with the FY18 SOT basis as discussed above, the primary updates reflected here focus on the conversion MFSP ramifications attributed to the updated FY19 cultivation yields, seasonal flows, and biomass costs (MBSP) upstream. All pertinent details for those parameters are summarized in the accompanying FY19 algal biomass SOT report [18]; in summary, FY19 algae farm MBSPs were estimated at $\$ 764 /$ ton or $\$ 670 /$ ton AFDW for the ASU vs FA evaporation scenarios respectively (unlined ponds, increasing to $\$ 961 /$ ton or $\$ 866 /$ ton for fully lined ponds, respectively). This was tied to a significant $36 \%$ improvement in annual cultivation productivity, $15.9 \mathrm{~g} / \mathrm{m}^{2} /$ day, over the FY18 basis of $11.7 \mathrm{~g} / \mathrm{m}^{2} /$ day, albeit at a higher seasonal variability of 4.2:1 between summer vs winter cultivation seasons. Beyond a lower biomass feedstock cost, the FY19 SOT update also reflects the associated higher throughputs through the CAP processing facility (roughly 116,000 tons/year versus 85,000 tons/year in FY18 tied to a fixed 5,000 acre algae farm facility), incurring economy of scale improvements for CAP processing.

Consistent with the FY18 SOT, variability in biomass delivery rates from upstream seasonal cultivation is mitigated by diverting excess peak biomass capacity to a wet anaerobic storage process, to be blended with biomass from cultivation during low production seasons, targeting a fixed throughput rate through the CAP facility all year. The wet storage concept and associated data is based on collaborations with partners at INL who have been coordinating work on this subject over recent years [9]. All details regarding storage degradation losses and compositional shifts are maintained consistently with the FY18 SOT basis, namely a 23\% storage degradation loss of whole biomass, roughly $17 \%$ of which goes to production of organic acids and the remainder presumed to $\mathrm{CO}_{2}$, as published in [9]. The fresh and stored biomass compositions are summarized in Table 2, based on inputs from INL extrapolated to fractional adjustments to the HCSD composition basis assumed here. The resulting raw seasonal and post-storage biomass flowrates are depicted in Figure 2. At the 4.2:1 seasonal variability from cultivation, roughly $25 \%$ of total annual biomass production must be sent to seasonal storage, which coupled with the $23 \%$ storage degradation losses, translates to $6 \%$ overall loss of annual biomass feed to the CAP facility. More recent (unpublished) experimental data from INL has indicated the potential for slight improvements to storage losses, reducing from $23 \%$ to $16 \%$ biomass degradation [personal communication, Brad Wahlen/Lynn Wendt (INL), November 2019]; updated storage data will be incorporated into future SOT updates, but as a preliminary sensitivity, such fractional reductions in storage losses would be estimated to reduce base case MFSPs by roughly $\$ 0.18 / \mathrm{GGE}(2 \%)$. The acid degradation products are not currently included in conversion yields to fuels, i.e. for the acids fermentation pathway (primarily focused on butyric acid), and ultimately are relegated to AD. 
Table 2. Input Compositions to CAP Models before and after Wet Storage Losses, based on Raw HCSD Composition as well as Adjustments Applied to the HCSD Baseline to Reflect Degradation Losses as Measured by INL [9], [19]

\begin{tabular}{lll}
\hline & Raw Algae & Wet Storage Algae \\
\hline Solids Content (wt\%) & $20 \%$ & $20 \%$ \\
& & \\
Algae Composition (wt\%) & 13.2 & 14.2 \\
Protein & 26.0 & 27.5 \\
FFA & 2.4 & 3.1 \\
Ash & 47.8 & 46.2 \\
Fermentable carbohydrates & 3.2 & 1.7 \\
Non-fermentable carbohydrates & 3.0 & 3.0 \\
Glycerol & 1.0 & 1.0 \\
Sterol & 1.8 & 1.8 \\
Non-fuel polar lipid impurities & 1.6 & 1.6 \\
Cell mass & 100.0 & 100.0 \\
\hline Sum & 1.0 & 0.77 \\
Whole algal biomass intact after storage (kg) & & \\
\hline Acid produced per kg of whole algae (after storage) & & 0.090 \\
Succinic acid, kg & & 0.083 \\
Lactic acid, kg & & \\
\hline
\end{tabular}

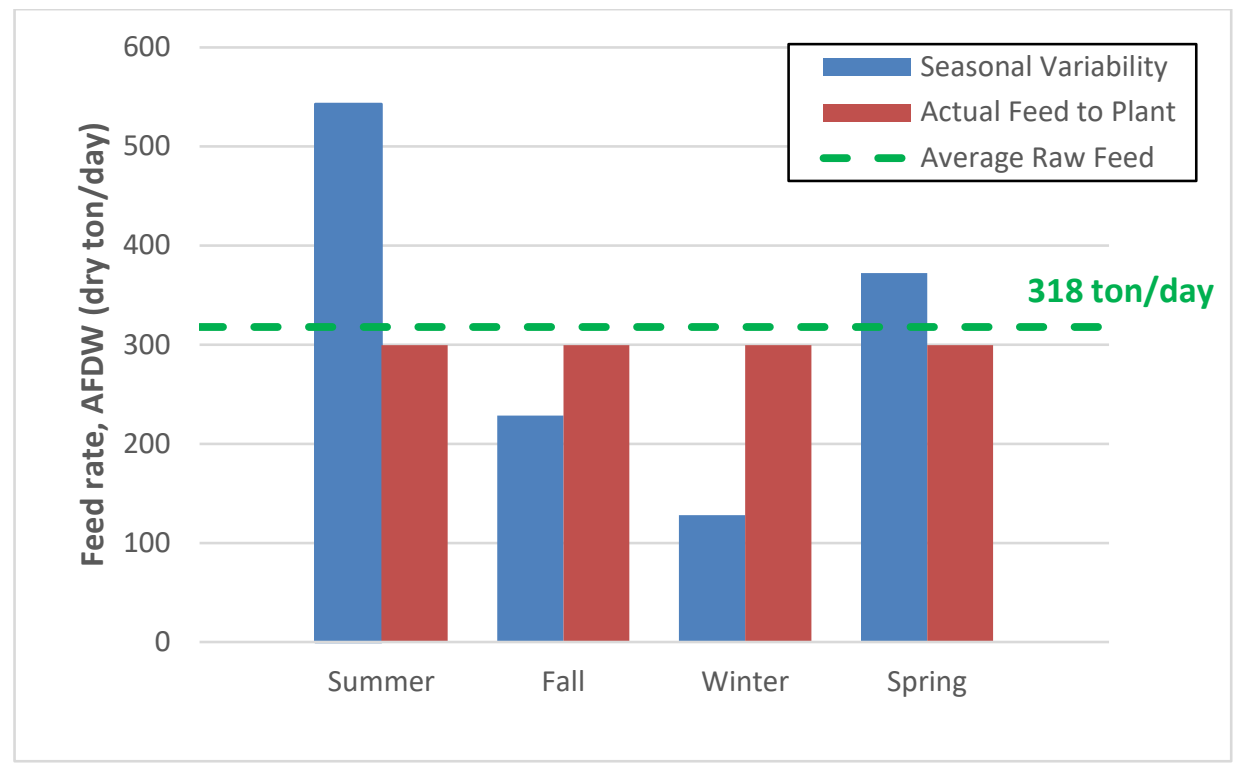

Figure 2. Seasonal and annual average feed rates to conversion facility (AFDW basis).

SOT basis assumes seasonal storage scenario represented by red bars (lower than annual average of blue bars due to seasonal storage losses) 


\section{Results}

\section{TEA Results}

After applying the resulting biomass flowrates and MBSP costs from the upstream biomass production model (see accompanying biomass SOT report) into the downstream CAP conversion model, the resulting overall SOT MFSP costs are summarized below in Figure 3 for the present FY19 SOT across both the acids and BDO fermentation pathways and for both the ASU and Florida Algae (FA) evaporation rate assumptions under upstream biomass cultivation. The results of this analysis indicate an FY19 SOT MFSP of \$10.53/GGE (acids pathway) or \$10.91/GGE (BDO pathway) for the ASU evaporation MBSP basis, or \$9.50/GGE and \$9.88/GGE (acids versus BDO) for the Florida Algae (FA) evaporation basis (all results in 2016\$). These costs increase to $\$ 12.68 / \mathrm{GGE}$ and $\$ 13.05 / \mathrm{GGE}$ for the fully-lined pond basis for the acids and BDO cases respectively, tied to the ASU evaporation MBSP scenario. Compared to the FY18 SOT at $\$ 12.70$ - $\$ 13.11$ for ASU evaporation or $\$ 11.28-\$ 11.70$ for FA evaporation (acids - BDO pathways respectively) based on updated back-cast FY18 cases, this represents a $16 \%-17 \%$ overall reduction in MFSP $(\$ 1.8-\$ 2.2 / \mathrm{GGE})$ for the two fermentation pathways as may be directly attributed to the improved upstream biomass cultivation performance in FY19. As noted above and consistent with prior SOTs, these values (for both MBSPs and MFSPs) are all based on the assertion of a fixed algal biomass composition consistent with NREL's HCSD future target projections (i.e., asserting an early stage of nutrient depletion with reduced protein content [13\%], mid-level FAME lipid content [26\%], and high carbohydrate content [48\%]) [3], [8].

Between the two fermentation pathways, the acids pathway SOT continues to reflect a slightly lower MFSP than the BDO pathway, driven by comparable yields and operating costs but $14 \%$ lower total capital costs (driven primarily by lower fermentation and upgrading costs, with aqueous BDO upgrading particularly costly at the low 7.3\% BDO concentration levels reflected in the present SOT). Given further improvements in BDO fermentation yields and use of more concentrated sugars (i.e. increased pretreatment sugar yields or higher sugar concentrations targeted through evaporation), the MFSP difference between the two fermentation pathways could reduce further. 


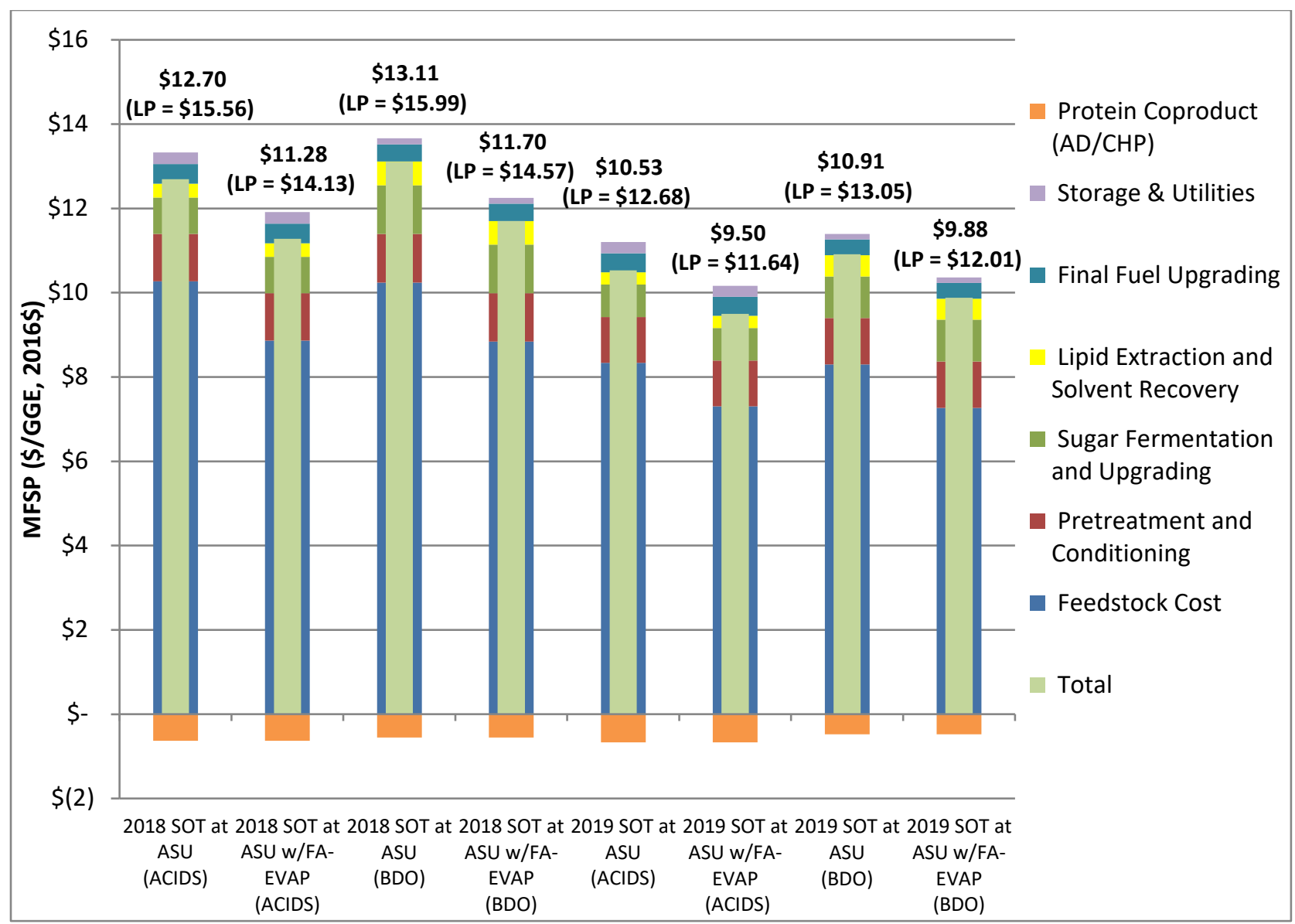

Figure 3. TEA results for 2018-2019 SOTs across both fermentation pathways (acids vs BDO) and cultivation evaporation scenarios (ASU vs FA evaporation MBSP).

Alternative MFSPs assuming fully-lined ponds are shown in parentheses (LP = lined ponds).

Figure 4 provides the same MFSP cost breakdowns for the SOT cases as shown in Figure 3, but formatted for simplicity reflecting only the FA evaporation cases, and also including example future projection scenarios for 2025 and 2030 reflecting the introduction of PU coproducts from a fraction of the algal lipids. As noted in the updated harmonization report and elsewhere, PUs represent a new coproduct option of interest to NREL given large market sizes and also high market values [5]. The future scenarios assume continued improvement in CAP process parameters if this CAP process configuration were to be further pursued (instead of or alongside the "new" CAP configuration discussed earlier), and further improvements in biomass cultivation performance (discussed in the accompanying algal biomass SOT report) in addition to the inclusion of PU co-production. While strictly intended to serve as examples, the 2025 case reflects an interim biomass yield of 30 ton/acre-yr $\left(20 \mathrm{~g} / \mathrm{m}^{2} /\right.$ day at 330 days/year $)$ and a conversion yield of $80 \mathrm{GGE} /$ ton biomass. The final 2030 example cases demonstrate a viable path to ultimately achieve the BETO MFSP targets of $\$ 2.5 / \mathrm{GGE}$ or lower, based solely on algal biomass, while capitalizing on the multi-fuel/product biorefinery concept of interest to BETO and avoiding small-market "niche" coproducts. That case assumes the same CAP processing targets as 2025 but with further reduced biomass costs tied to further improved cultivation performance. 
As discussed above, we again note here that the PU co-production bars included under future out-year cases for 2025 and 2030 in Figure 4 are intended to demonstrate proof-of-concept examples for the ability to valorize a portion of algal lipids for high-value PU production, based to date on a better-understood TEA modeling framework reflective of isocyanate-based foam PU processing (and associated market values). Given that such technology is reasonably wellunderstood, being pursued commercially, and makes use of toxic isocyanates, NREL experimental work is not currently investigating such PU product routes. Instead, recent NREL work has focused on a more novel carbonation/diamine cross-linking route to yield nonisocyanate polyurethanes with the potential to enable fully-renewable chemistries. Good initial progress has been made under that route, and we defer to the associated experimental project reports for a full accounting of that work and resultant data [21]. In summary, initial work found very rapid kinetics for NIPU synthesis when conducted on algal PUFA substrates, with over $80 \%$ conversion of carbonated groups within the first 5 minutes and complete conversion in 30 minutes, given those substrates being highly reactive with many sites for epoxidation (resulting in solid/brittle end-products, without measurable viscosities). However, the work identified ways to control the reaction rates through limiting the degree of carbonation, with PUFA substrates at low-to-medium carbonation degrees leading to NIPU products with measurable viscosities (varying significantly between 10-3900 cP). Carbonated algal PUFA substrates also were seen leading to NIPU products ranging from very low to high tensile strength (1-570 Mpa Young's Modulus). Still, given key gaps and uncertainties related to processing costs, manufacturing logistics, and product values for the NIPU route, NIPU coproduct is not currently reflected in the present SOT, but will be an important area for future work moving forward.

As discussed in other recent work [20], we reiterate that the future projection scenarios shown in Figure 4 are by no means the only possible combinations of coproducts that support achieving less than $\$ 2.5 / \mathrm{GGE}$ algal fuel goals, but are initial examples that demonstrate proof-of-concept based on recent activities to select these products for further TEA consideration. Likewise, NREL's new CAP processing concept, although still under development, is also envisioned to enable an alternative path to meeting such out-year MFSP goals under a different process configuration, assuming current challenges with respect to MOT/catalytic upgrading can be further optimized [10]. Finally, Table 3 provides key technical and cost details associated with the various cases presented in Figure 4. This table shows that room for improvement exists moving forward beyond the current SOT baseline, particularly with respect to cultivation productivity (57\% improvement), but also for key cost drivers in CAP conversion based on the current configuration, including pretreatment sugar yields (22\% improvement) and sugar fermentation/upgrading yields (26\% and 50\% improvement in the acids [targeting butyric acid exclusively] and BDO pathways respectively). Lipid extraction and upgrading yields have essentially achieved final target levels, but further room for improvement exists i.e. around catalyst robustness and resistance to deactivation. Note that the "conversion" contribution to MFSP for the 2025-2030 projection cases in Table 3 reflects the net sum of all conversion process costs ("positive" bars in Figure 4) combined with the coproduct processing costs and revenues ("negative" bars in Figure 4), thus the conversion MFSP values on the order of negative $\$ 3 / \mathrm{GGE}$ or more for the future projection cases indicate that all non-feedstock conversion costs are outweighed by larger coproduct revenues, as required to compensate for high biomass costs inherent to microalgae farming. Finally, moving forward other alternative CAP configurations will be investigated as well, including the new CAP approach discussed previously or other variants that may support higher-protein algal biomass feedstocks. 


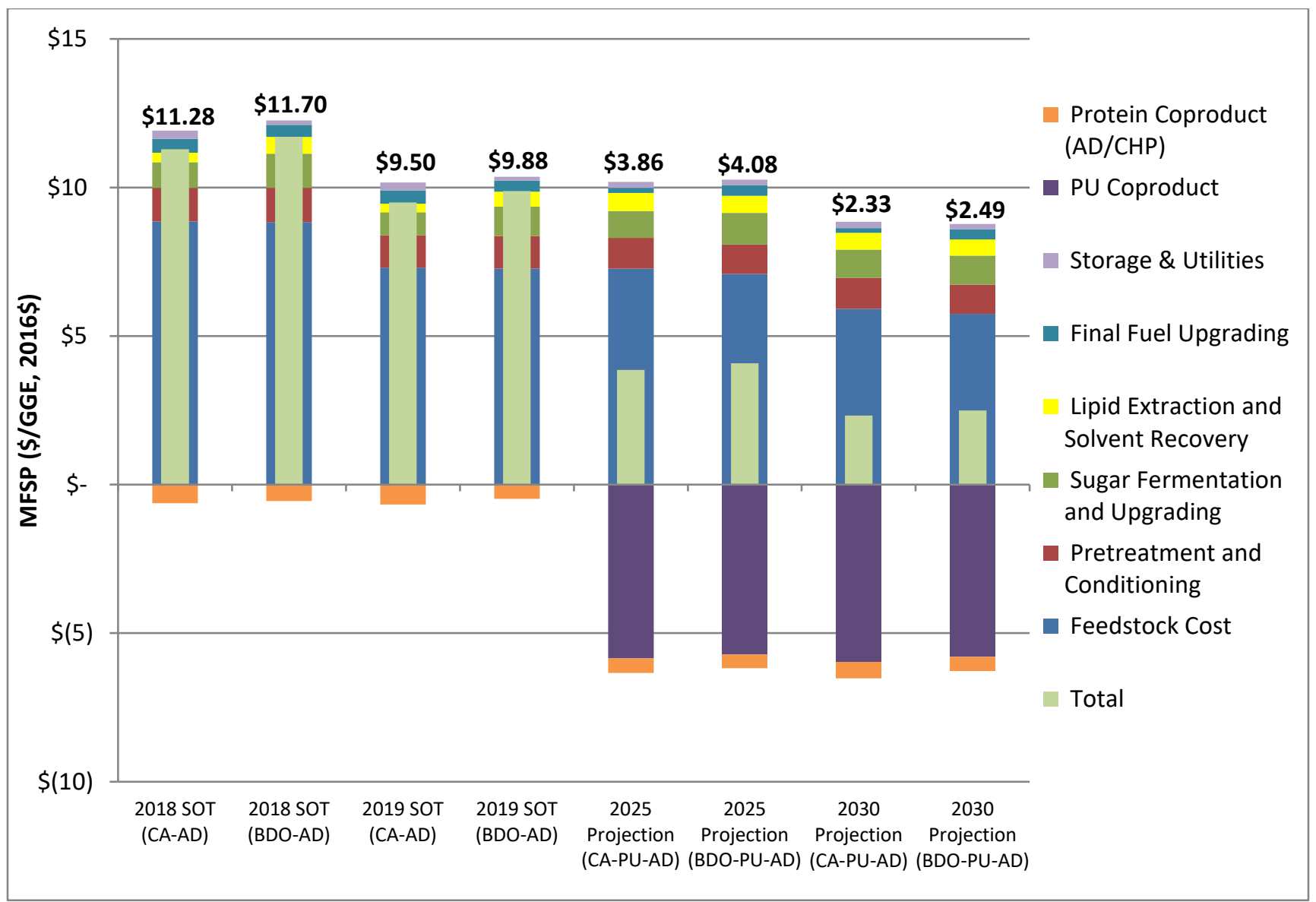

Figure 4: Summary of MFSP cost breakdowns for SOTs and future example projection scenarios (FA evap scenarios)

(CA = sugar fermentation/upgrading to fuels via carboxylic acid intermediates; BDO = sugar fermentation/upgrading to fuels via 2,3-BDO intermediates; PU = polyurethanes derived from unsaturated fatty acid fraction of lipids; all cases currently assume anaerobic digestion of protein residues, reflecting CAP configuration as depicted in Figure 1) 
Table 3: Technical Overview Table for Cost and Process Metrics Associated with FY18-FY19 SOT Cases, Compared to Example 20252030 Projection Scenarios based on Introduction of PU Coproducts (Costs in 2016\$). SOT Cases only reflect FA Evaporation Scenarios for Simplicity.

\begin{tabular}{|c|c|c|c|c|c|c|c|c|}
\hline Metric & $\begin{array}{l}2018 \text { SOT } \\
\text { (Acids) - } \\
\text { FA Evap }\end{array}$ & $\begin{array}{c}2018 \text { SOT } \\
\text { (BDO) - } \\
\text { FA Evap }\end{array}$ & $\begin{array}{l}2019 \text { SOT } \\
\text { (Acids) - } \\
\text { FA Evap }\end{array}$ & $\begin{array}{c}2019 \text { SOT } \\
\text { (BDO) - } \\
\text { FA Evap }\end{array}$ & $\begin{array}{c}2025 \\
\text { Projection } \\
\text { (Acids-PU) }\end{array}$ & $\begin{array}{l}2025 \\
\text { Projection } \\
\text { (BDO-PU) }\end{array}$ & $\begin{array}{l}2030 \\
\text { Projection } \\
\text { (Acids-PU) }\end{array}$ & $\begin{array}{c}2030 \\
\text { Projection } \\
\text { (BDO-PU) }\end{array}$ \\
\hline MFSP (\$/GGE, 2016\$) ${ }^{a}$ & $\begin{array}{c}\$ 11.28 \\
{[\$ 14.13]}\end{array}$ & $\begin{array}{c}\$ 11.70 \\
{[\$ 14.57]}\end{array}$ & $\begin{array}{c}\$ 9.50 \\
{[\$ 11.64]}\end{array}$ & $\begin{array}{c}\$ 9.88 \\
{[\$ 12.01]}\end{array}$ & $\$ 3.86$ & $\$ 4.08$ & $\$ 2.33$ & $\$ 2.49$ \\
\hline Feedstock Contribution (\$/GGE, 2016\$) ${ }^{a}$ & $\begin{array}{c}\$ 8.86 \\
{[\$ 11.71]}\end{array}$ & $\begin{array}{c}\$ 8.84 \\
{[\$ 11.71]}\end{array}$ & $\begin{array}{c}\$ 7.30 \\
{[\$ 9.44]}\end{array}$ & $\begin{array}{c}\$ 7.27 \\
{[\$ 9.40]}\end{array}$ & $\$ 7.27$ & $\$ 7.09$ & $\$ 5.92$ & $\$ 5.74$ \\
\hline Conversion Contribution (\$/GGE, 2016\$)a & $\begin{array}{c}\$ 2.42 \\
{[\$ 2.42]}\end{array}$ & $\begin{array}{c}\$ 2.86 \\
{[\$ 2.86]}\end{array}$ & $\begin{array}{c}\$ 2.20 \\
{[\$ 2.20]}\end{array}$ & $\begin{array}{c}\$ 2.61 \\
{[\$ 2.61]}\end{array}$ & $(\$ 3.42)$ & $(\$ 3.00)$ & $(\$ 3.59)$ & $(\$ 3.25)$ \\
\hline Yield (GGE/ton AFDW) & 92.3 & 92.5 & 91.0 & 91.4 & 82.1 & 84.3 & 81.8 & 84.3 \\
\hline Renewable Diesel Blend-Stock Yield (GGE/ton AFDW) & 54.4 & 65.1 & 53.7 & 64.2 & 31.5 & 52.2 & 31.5 & 52.2 \\
\hline Naphtha Yield (GGE/ton AFDW) & 37.8 & 27.4 & 37.3 & 27.2 & 50.6 & 32.1 & 50.4 & 32.2 \\
\hline Finished Fuel Products Yield (GGE/acre/yr) & 1,573 & 1,577 & 2,105 & 2,114 & 2,389 & 2,520 & 2,988 & 3,146 \\
\hline C Yield to Fuels from Biomass & $46.1 \%$ & $44.3 \%$ & $46.3 \%$ & $43.7 \%$ & $39.3 \%$ & $40.2 \%$ & $39.2 \%$ & $40.2 \%$ \\
\hline C Yield to Coproducts from Biomass & NA & NA & NA & NA & $14.5 \%$ & $14.5 \%$ & $14.5 \%$ & $14.5 \%$ \\
\hline \multicolumn{9}{|l|}{ Feedstock } \\
\hline Feedstock Cost (\$/ton AFDW)a & $\begin{array}{c}\$ 824 \\
{[\$ 1,090]^{b}}\end{array}$ & $\begin{array}{c}\$ 824 \\
{[\$ 1,090]^{b}}\end{array}$ & $\begin{array}{c}\$ 670 \\
{[\$ 866]^{b}}\end{array}$ & $\begin{array}{c}\$ 670 \\
{[\$ 866]^{b}}\end{array}$ & $\$ 602$ & $\$ 602$ & $\$ 488$ & $\$ 488$ \\
\hline Year-Average Cultivation Productivity (g/m²/day AFDW) & 11.7 & 11.7 & 15.9 & 15.9 & 20 & 20 & 25 & 25 \\
\hline Max Seasonal Variability (max:min productivity) & $2.0: 1$ & $2.0: 1$ & $4.2: 1$ & $4.2: 1$ & $3.0: 1$ & $3.0: 1$ & $3.0: 1$ & $3.0: 1$ \\
\hline Harvested Biomass Lipid Content (dry wt\% as FAME) & $26 \%$ b & $26 \%$ b & $26 \%$ b & $26 \%$ & $26 \%$ & $26 \%$ & $26 \%$ & $26 \%$ \\
\hline Harvested Biomass Concentration (g/L AFDW) & 0.51 & 0.51 & 0.49 & 0.49 & 0.5 & 0.5 & 0.5 & 0.5 \\
\hline \multicolumn{9}{|l|}{ Pretreatment + Conditioning } \\
\hline Solids Loading (wt\%) & $20 \%{ }^{c}$ & $20 \%{ }^{c}$ & $20 \%{ }^{c}$ & $20 \%{ }^{c}$ & $20 \%$ & $20 \%$ & $20 \%$ & $20 \%$ \\
\hline Acid Loading (wt\% versus feed water rate) & $2 \%$ & $2 \%$ & $2 \%$ & $2 \%$ & $1 \%$ & $1 \%$ & $1 \%$ & $1 \%$ \\
\hline Fermentable Sugar Release ("glucose yield”) & $74 \%$ & $74 \%$ & $74 \%$ & $74 \%$ & $90 \%$ & $90 \%$ & $90 \%$ & $90 \%$ \\
\hline Glucan to Degradation Products & $1.5 \%$ & $1.5 \%$ & $1.5 \%$ & $1.5 \%$ & $0.3 \%$ & $0.3 \%$ & $0.3 \%$ & $0.3 \%$ \\
\hline Hydrolysate solid-liquid separation & Yes & Yes & Yes & Yes & Yes & Yes & Yes & Yes \\
\hline
\end{tabular}




\begin{tabular}{|c|c|c|c|c|c|c|c|c|}
\hline Metric & $\begin{array}{l}2018 \text { SOT } \\
\text { (Acids) - } \\
\text { FA Evap }\end{array}$ & $\begin{array}{c}2018 \text { SOT } \\
\text { (BDO) - } \\
\text { FA Evap }\end{array}$ & $\begin{array}{l}2019 \text { SOT } \\
\text { (Acids) - } \\
\text { FA Evap }\end{array}$ & $\begin{array}{c}2019 \text { SOT } \\
\text { (BDO) - } \\
\text { FA Evap }\end{array}$ & $\begin{array}{l}2025 \\
\text { Projection } \\
\text { (Acids-PU) }\end{array}$ & $\begin{array}{c}2025 \\
\text { Projection } \\
\text { (BDO-PU) }\end{array}$ & $\begin{array}{l}2030 \\
\text { Projection } \\
\text { (Acids-PU) }\end{array}$ & $\begin{array}{c}2030 \\
\text { Projection } \\
\text { (BDO-PU) }\end{array}$ \\
\hline \multicolumn{9}{|l|}{ Sugar Fermentation + Catalytic Upgrading } \\
\hline Fermentation Productivity (g/L-hr) & 0.3 & $\begin{array}{l}1.3(56 \mathrm{hr} \\
\text { batch time })\end{array}$ & 0.3 & $\begin{array}{l}1.3(56 \mathrm{hr} \\
\text { batch time })\end{array}$ & 2.0 & $\begin{array}{l}2.0(36 \mathrm{hr} \\
\text { batch time })\end{array}$ & 2.0 & $\begin{array}{l}2.0(36 \mathrm{hr} \\
\text { batch time })\end{array}$ \\
\hline Product titer (g/L) & $N A^{d}$ & 73 & $N^{d}$ & 73 & $N^{d}$ & 90 & $N^{d}$ & 90 \\
\hline Glucose to Product & $92 \%$ & $74 \%$ & $92 \%$ & $74 \%$ & $95 \%$ & $95 \%$ & $95 \%$ & $95 \%$ \\
\hline Mannose to Product & $92 \%$ & $55 \%$ & $92 \%$ & $55 \%$ & $95 \%$ & $95 \%$ & $95 \%$ & $95 \%$ \\
\hline Glycerol to Product & $92 \%$ & $0 \%$ & $92 \%$ & $0 \%$ & $95 \%$ & $95 \%$ & $95 \%$ & $95 \%$ \\
\hline Overall Fermentation Yield to Product (g/g total sugars) & 0.48 & 0.34 & 0.48 & 0.34 & 0.48 & 0.51 & 0.48 & 0.51 \\
\hline Catalytic Upgrading Yield to HDO Feed (wt\% of feed)e & $53 \%$ & $60 \%$ & $53 \%$ & $60 \%$ & $55 \%$ & $61 \%$ & $55 \%$ & $61 \%$ \\
\hline Catalytic Upgrading Carbon Yield to HDO Feede & $57 \%$ & $56 \%$ & $57 \%$ & $56 \%$ & $81 \%$ & $82 \%$ & $81 \%$ & $82 \%$ \\
\hline \multicolumn{9}{|l|}{ Lipid Processing } \\
\hline Solvent Loading (nonpolar:EtOH:dry biomass ratio, wt) & $2.7: 1.1: 1$ & $2.7: 1.1: 1$ & $2.7: 1.1: 1$ & $2.7: 1.1: 1$ & 2.7:1.1:1 & $2.7: 1.1: 1$ & $2.7: 1.1: 1$ & $2.7: 1.1: 1$ \\
\hline Total Convertible Lipid Extraction Yield & $96 \%$ & $96 \%$ & $96 \%$ & $96 \%$ & $96 \%$ & $96 \%$ & $96 \%$ & $96 \%$ \\
\hline Lipid Impurity Partition to Extract & $<11.5 \%$ & $<11.5 \%$ & $<11.5 \%$ & $<11.5 \%$ & $<11.5 \%$ & $<11.5 \%$ & $<11.5 \%$ & $<11.5 \%$ \\
\hline $\begin{array}{l}\text { Fuel Finishing Renewable Diesel Blend-Stock Yield (wt\% } \\
\text { of total feed) }\end{array}$ & $51.9 \%$ & $60.6 \%$ & $51.9 \%$ & $60.6 \%$ & $34.2 \%$ & $53.7 \%$ & $34.2 \%$ & $53.7 \%$ \\
\hline Fuel Finishing Naphtha Yield (wt\% of total feed) ${ }^{f}$ & $35.9 \%$ & $25.3 \%$ & $35.9 \%$ & $25.3 \%$ & $56.6 \%$ & $34.3 \%$ & $56.6 \%$ & $34.3 \%$ \\
\hline Fuel Finishing $\mathrm{H}_{2}$ Consumption (wt\% of total feed) ${ }^{f}$ & $3.2 \%$ & $3.0 \%$ & $3.2 \%$ & $3.0 \%$ & $3.0 \%$ & $2.7 \%$ & $3.0 \%$ & $2.7 \%$ \\
\hline \% Lipid Diversion to Polyurethane Coproduct (\%) & NA & NA & NA & NA & $46 \%$ & $46 \%$ & $46 \%$ & $46 \%$ \\
\hline Overall Polyurethane Yield from Algae (wt\% afdw) & NA & NA & NA & NA & $22 \%$ & $22 \%$ & $22 \%$ & $22 \%$ \\
\hline \multicolumn{9}{|l|}{ Protein/Stillage Processing } \\
\hline N/P Recycle to Ponds ( $\%$ of biomass feed to CAP) & $100 \% / 50 \%$ & $100 \% / 46 \%$ & $100 \% / 50 \%$ & $100 \% / 46 \%$ & $100 \% / 54 \%$ & $100 \% / 51 \%$ & $100 \% / 54 \%$ & $100 \% / 51 \%$ \\
\hline AD Biogas Yield ( $\left.\mathrm{L} \mathrm{CH}_{4} / \mathrm{g} \mathrm{TS}\right)$ & 0.26 & 0.25 & 0.26 & 0.25 & 0.28 & 0.27 & 0.28 & 0.27 \\
\hline
\end{tabular}

a First values represent unlined pond base case, values in brackets represent fully lined pond scenario

b SOT based on ASU production of Nannochloropsis, Scenedesmus, Monoraphidium, and/or Desmodesmus (as applicable) overlaid with target HCSD composition

c Experimental work conducted at pretreatment solids content varying around $20 \%$, expected to perform the same as $20 \%$.

d Acids fermentation case based on continuous in situ acid removal across pertraction membrane

e Represents overall catalytic upgrading yield of fermentation intermediate (after recovery) through feed to final fuel finishing (hydrotreating) step

f Final "fuel finishing" step is a combined hydrotreater to upgrade lipids plus the final intermediate from the sugar conversion train 


\section{Sustainability Metric Indicators}

In addition to the TEA results noted above, here we also report on associated sustainability "indicators" attributed to the algae CAP SOT model. In keeping with recent BETO guidance for all formal life cycle assessment sustainability metrics to be handled by Argonne National Laboratory to ensure no inconsistencies in such metrics versus NREL-calculated values (i.e. using GREET versus SimaPro), we avoid reporting on life cycle assessment parameters such as greenhouse gas emissions or fossil energy consumption in this report (but are currently working to provide the input/output inventories to partners at Argonne National Laboratory). Instead, Table 4 summarizes key sustainability indicators as may be taken directly from the Aspen Plus process. Namely, for the CAP conversion SOT this includes mass and carbon yield to fuels, carbon yield to coproducts (not applicable in this current SOT), facility power and natural gas demands, and freshwater demands for the conversion process. While most of the parameters are fairly comparable between the two pathways, the acids pathway requires more heat and thus a higher natural gas import which is co-fired in the AD biogas turbine, but which in turn also leads to more power generation through the turbine that translates to a larger net power export versus the BDO pathway. The process input/output inventories furnished to Argonne National Laboratory for subsequent life cycle assessment supply chain sustainability analysis (SCSA) are summarized in Appendix B.

Table 4. Sustainability Indicators for FY19 SOT CAP Models

\begin{tabular}{|l|l|c|c|}
\cline { 3 - 4 } \multicolumn{2}{c|}{} & \multicolumn{2}{c|}{ FY19 SOT Fermentation Pathway } \\
\hline Parameter & Acids & BDO \\
\hline Fuel Yield by Weight of Biomass & GGE per dry ton biomass & 91.0 & 91.4 \\
\hline Carbon Efficiency to Fuels & $\%$ C in feedstock & $46.3 \%$ & $43.7 \%$ \\
\hline Carbon Efficiency to Coproduct & $\%$ C in feedstock & NA & NA \\
\hline Electricity Import & kWh/GGE & -3.59 (export) & -0.52 (export) \\
\hline Natural Gas Import & MJ/GGE & 36.3 & 16.4 \\
\hline Water Consumption & $\mathrm{m} /$ day & 1,235 & 1,664 \\
\hline Water Consumption & gal/GGE & 10.2 & 13.7 \\
\hline
\end{tabular}




\section{Concluding Remarks}

Running the FY19 SOT biomass costs (MBSPs) and associated yields from the front-end algae farm model through the CAP configurations and underlying performance parameters consistent with the latest FY18 CAP SOT cases translates to an estimated FY19 SOT minimum fuel selling price of \$10.53/GGE (acids pathway) or \$10.91/GGE (BDO pathway) for the ASU evaporation MBSP basis, or \$9.50/GGE and \$9.88/GGE (acids versus BDO) for the FA evaporation basis (all results in 2016\$) for the unlined pond base case. SOT fuel costs for the alternative fully lined pond scenario would increase to $\$ 12.68 / \mathrm{GGE}$ or $\$ 13.05 / \mathrm{GGE}$ for the acids and BDO cases under baseline ASU evaporation rates. The MFSP cost is influenced heavily by the cost of upstream biomass production, accounting for roughly $74-79 \%$ of total MFSPs in the unlined pond base case. Relative to the FY18 SOT at $\$ 12.70-\$ 13.11$ for ASU evaporation or $\$ 11.28$ - \$11.70 for FA evaporation (acids - BDO pathways respectively) based on updated back-cast FY18 cases, this represents a 16\%-17\% overall reduction in MFSP (\$1.8-\$2.2/GGE) for the two fermentation pathways as may be directly attributed to the improved upstream biomass cultivation performance in FY19. Between the two sugar fermentation pathways for intermediate fuel precursor production, the acids pathway continues to indicate slightly lower MFSPs in the present SOT (roughly $\$ 0.38 /$ GGE lower for acids than BDO), primarily due to better fermentation performance/yields towards acids, the preliminary and not-optimized nature of the Zymomonas BDO strain engineered for mannose utilization, and lower acids upgrading costs. Moving forward, this difference would likely shrink as BDO fermentation were to improve or conditions were further optimized for higher titers.

Beyond current SOT benchmarks, to increase yields and reduce MFSP cost on the conversion side moving forward under this CAP configuration reflected here, further room exists to optimize pretreatment conditions and improve fermentable sugar yields (i.e. carbohydrate hydrolysis to monomeric sugars and fermentation yield to butyric acid or BDO while minimizing side byproducts such as acetic acid or acetoin respectively), which may be achieved in one instance by potentially reducing acid loading and targeting increased sugar oligomers followed by a lowcost oligomer "hold" step to convert oligomers to fermentable monomers. Additionally, while lipid extraction and upgrading yields have been demonstrated near their final goals for this CAP approach, further room for improvement exists around improving catalyst stability and activity for HDO plus HI functionalities in the presence of algal lipid impurities, and on better understanding ramifications on hydrotreater design for co-processing both lipids and the final intermediate compounds from sugar train upgrading through the same fuel finishing reactor.

Finally, new coproducts hold significant promise to more dramatically lower MFSPs, such as polyurethanes from fractions of the lipid component, which will be key to reduce MFSPs beyond maximum performance thresholds for fuel production train steps under any CAP configuration. Promising results have recently been demonstrated by NREL for non-isocyanate polyurethane production, which may be incorporated under future SOT iterations but first would require a better understanding of key processing design/cost considerations as well as product applications and values for such a material (this will represent an area for further work moving forward). Future experimental plans also intend to begin investigating alternative CAP processing schemes for different algal biomass compositions, including more optimal uses of algal protein. In 2019 such alternative processing strategies began to be pursued experimentally, starting first with nutrient deplete (high-carbohydrate/high-lipid) biomass, and demonstrating preliminary proof of 
concept for key new unit operations exhibiting an ability to co-convert both carbohydrates and protein into fuel precursors. However, early experimental work has so far only demonstrated reasonable yields at impractically low solids concentrations, thus not yet representing a realistic basis for incorporation into SOT benchmarking updates at present. Moving forward a number of options will be pursued to better understand and optimize those processing steps, and additionally to consider modifications to the process to accommodate and better valorize highprotein biomass. Those efforts would provide important "risk mitigation" strategies for the CAP pathway in the event that the targeted HCSD-type compositions could not be achieved as projected and instead cultivation trials continued to produce higher-protein/lower-lipid biomass for the foreseeable future. Upon completion of an initial technical report documenting TEA potential for such new CAP strategies for high-carbohydrate biomass (in progress), we are planning to establish a second similar report focused on implications for high-protein biomass. In all cases, inclusion of one or more value-added coproducts with sufficiently large market volumes will continue to be a central element of all such TEA studies to highlight paths towards achieving BETO goals of $\$ 2.5 / \mathrm{GGE}$ algal biofuels while supporting commodity-scale deployment of such algal biorefinery concepts. 


\section{References}

NREL milestone reports cited below cannot be accessed outside of NREL and DOE. Readers may contact the authors of those reports to determine if this information has been made public since publication of this report.

1. AspenPlus2007 7.2. Cambridge MA. http://www.aspentech.com.

2. Davis, R., C. Kinchin, J. Markham, E. C. D. Tan, L. M. L. Laurens, D. Sexton, D. Knorr, P. Schoen, and J. Lukas. Process Design and Economics for the Conversion of Algal Biomass to Biofuels: Algal Biomass Fractionation to Lipid-and Carbohydrate-Derived Fuel Products. NREL/TP-5100-62368. Golden, CO: National Renewable Energy Laboratory, 2014. Available: https://www.nrel.gov/docs/fy14osti/62368.pdf.

3. Davis, R., J. Markham, C. Kinchin, N. Grundl, E. C. D. Tan, and D. Humbird. Process Design and Economics for the Production of Algal Biomass: Algal Biomass production in Open Pond Systems and Processing Through Dewatering for Downstream Conversion. NREL/TP-510064772. Golden, CO: National Renewable Energy Laboratory, 2016. Available: http://www.nrel.gov/docs/fy16osti/64772.pdf.

4. Davis, R., N. Grundl, L. Tao, M. J. Biddy, E. C. D. Tan, G. T. Beckham, D. Humbird, D. N. Thompson, and M. S. Roni. Process Design and Economics for the Conversion of Lignocellulosic Biomass to Hydrocarbon Fuels and Coproducts: 2018 Biochemical Design Case Update; Biochemical Deconstruction and Conversion of Biomass to Fuels and Products via Integrated Biorefinery Pathways. NREL/TP-5100-71949 Golden, CO: National Renewable Energy Laboratory, 2018. Available: https://www.nrel.gov/docs/fy19osti/71949.pdf.

5. Davis, R., A. Coleman, M. Wigmosta, J. Markham, C. Kinchin, Y. Zhu, S. Jones, C. Kinchin, J. Han, C. Canter, and Q. Li. 2017 Algae Harmonization Study: Evaluating the Potential for Future Algal Biofuel Costs, Sustainability, and Resource Assessment from Harmonized Modeling. ANL/ESD/18-12. Argonne, IL: Argonne National Laboratory; NREL/TP-5100-70715. Golden, CO: National Renewable Energy Laboratory; PNNL-27547. Richland, WA: Pacific Northwest National Laboratory, 2018. Available: https://www.nrel.gov/docs/fy18osti/70715.pdf.

6. Davis, R. Algal Biofuels Techno-Economic Analysis. Presented at the 2017 BETO Peer Review, Denver, CO, March 6, 2017. Available: https://www.energy.gov/sites/prod/files/2017/05/f34/algae_davis_131200.pdf

7. Davis, R. 1.3.5.200 Algal Biofuels Techno-Economic Analysis. Presented at the 2019 BETO Peer Review, Denver, CO, March 4, 2019. Available:

https://www.energy.gov/sites/prod/files/2019/03/f61/Algal\%20Biofuels\%20TechnoEconomic\%20Analysis_NL0021975.pdf.

8. Davis, R. and J. Markham. FY18 CAP Conversion SOT. NREL milestone report, 2018.

9. Wendt, L. M., C. Kinchin, B. D. Wahlen, R. Davis, T. A. Dempster, and H. Gerken. "Assessing the stability and techno-economic implications for wet storage of harvested microalgae to manage seasonal variability." Biotechnology for Biofuels, 2019. 12(1): p. 80. Available:

https://doi.org/10.1186/s13068-019-1420-0. 
10. Davis, R., M. Wiatrowski, and C. Kinchin. [DRAFT] Conceptual Basis and TechnoEconomic Modeling for Integrated Algal Biorefinery Conversion of Microalgae to Fuels and Products. Golden, CO: National Renewable Energy Laboratory, 2019 (draft in progress).

11. Nagle, N. and P.T. Pienkos. Large scale pretreatment of high lipid biomass from halotolerant strain as well as with algal biomass blended with brown grease. NREL milestone report, 2019.

12. Kruger, J. Integrated CAP processing of biomass and biomass/brown grease blend pretreated in Q2 to provide data for FY19 SOT. NREL milestone report, 2019.

13. Davis, R., A. Bartling, and L. Tao. FY19 Biochemical Conversion SOT Report. NREL milestone report, 2019.

14. Kruger, J., E. Christensen, T. Dong, and R. McCormick. Hydroprocessing of algal-biomassderived lipids to produce renewable diesel fuel. NREL milestone report, 2015.

15. Kruger, J. One-step Deoxygenation/Hydroisomerization of Algal Lipids. NREL milestone report, 2017.

16. Dong, T., N. Nagle, and P. Pienkos. CAP Process Research: Demonstrate efficacy of extraction process based on n-alkanes produced from algal lipids rather than hexane. NREL milestone report, 2017.

17. Knoshaug, E., R. Spiller, T. Dong, N. Nagle, D. Templeton, and P. Pienkos. CAP Process Research: Demonstrate conversion of algal sugars to carboxylates via fermentation with Clostridium butyricum. Monitor simultaneous conversion of amino acids into hydroxyacids. NREL milestone report, 2018.

18. Davis, R. FY19 Algal Biomass SOT. NREL milestone report, 2019.

19. Kinchin, C. Algal biomass storage TEA: Conduct preliminary TEA modeling on wet storage of thickened algal biomass (as an alternative to dry seasonal storage), to compare costs of two longterm wet storage options. NREL milestone report, 2017.

20. Laurens, L. M., J. Markham, D. W. Templeton, E. D. Christensen, S. Van Wychen, E. W. Vadelius, M. Chen-Glasser, T. Dong, R. Davis, and P. T. Pienkos. "Development of algae biorefinery concepts for biofuels and bioproducts; a perspective on process-compatible products and their impact on cost-reduction." Energy \& Environmental Science, 2017. 10(8): p. 1716-1738. Available: https://doi.org/10.1039/C7EE01306J.

21. Pienkos, P. T. Fully Renewable Polyurethane Resins Produced from Algae and Other Feedstocks. NREL milestone report, 2019. 


\section{Appendix A. TEA Summary Sheet for Base Case CAP SOT Benchmark Model}

\section{Appendix A1: TEA Summary Sheet for Base Case CAP SOT Benchmark Model: Acids Case (FA Evaporation MBSP Scenario, 2016- dollars)}

\section{Combined Algal Processing to Fuels and Bioproducts Process Engineering Analysis 2019 SOT for Biomass Based on Florida Algae Evaporation and CA Production}

\begin{tabular}{|c|c|}
\hline \multirow{2}{*}{$\begin{array}{r}\text { Cost Year Basis: } \\
\text { MFSP (Gasoline Equivalent Basis): }\end{array}$} & $2016 \$$ \\
\hline & $\$ 9.50$ /GGE \\
\hline Contributions: & $\$ 7.30 /$ GGE \\
\hline Conversion & $\$ 2.20 / G G E$ \\
\hline Total Fuel Production (RDB + Naphtha + Ethanol): & $10.52 \mathrm{MMGGE} / \mathrm{yr}$ \\
\hline RDB Production: & 6.21 MMGGE/yr \\
\hline Naphtha Production: & 4.32 MMGGE/yr \\
\hline Total Fuel Yield ( RDB + Naphtha + Ethanol: & 90.98 GGE / dry U.S. ton feedstock \\
\hline Feedstock Cost: & $\$ 670$ dry U.S. Ton algal biomass (ash free) \\
\hline Internal Rate of Return: & $10 \%$ \\
\hline Equity Percent of total Investment: & $40 \%$ \\
\hline
\end{tabular}

\begin{tabular}{|c|c|}
\hline \multicolumn{2}{|l|}{ Capital Costs } \\
\hline A100: Pretreatment and Conditioning & $\$ 23,500,000$ \\
\hline A200.CA: Carboxylic Acid Fermentation and Distillation & $\$ 14,500,000$ \\
\hline A300: Lipid Separation and Co-products & $\$ 7,200,000$ \\
\hline A400: Product Purification and Upgrading & $\$ 5,500,000$ \\
\hline A500: Protein/Residual Processing & $\$ 4,700,000$ \\
\hline A600: Combined Heat and Power & $\$ 5,100,000$ \\
\hline A700: Utilities \& Storage & $\$ 2,800,000$ \\
\hline Total Installed Equipment Cost & $\$ 63,300,000$ \\
\hline Added Direct + Indirect Costs & $\$ 59,700,000$ \\
\hline$(\%$ of $\mathrm{TCl})$ & $48.54 \%$ \\
\hline Total Capital Investment (TCl) & $\$ 123,000,000$ \\
\hline Installed Equiptment Cost/Annual GGE & $\$ 6.02$ \\
\hline Total Capital Investment/Annual GGE & $\$ 11.69$ \\
\hline Loan Rate & $8 \%$ \\
\hline Term(years) & 10 \\
\hline Capital Charge Factor (Computed) & 0.128 \\
\hline \multicolumn{2}{|l|}{ Carbon Retention Efficiencies: } \\
\hline Total Carbon Efficiency to Fuel Products & $46.3 \%$ \\
\hline \multicolumn{2}{|l|}{ (Fuel C/Biomass C) } \\
\hline RDB (RDB C/Biomass C) & $27.5 \%$ \\
\hline Naphtha (Naphtha C/Biomass C) & $18.8 \%$ \\
\hline \multicolumn{2}{|l|}{ Fuel Yields } \\
\hline Current RDB Production (U.S. ton/yr) & 19,112 \\
\hline Current Naphtha Production (U.S. ton/yr) & 13,233 \\
\hline
\end{tabular}

\begin{tabular}{|c|c|}
\hline \multicolumn{2}{|c|}{ Manufacturing Costs (cents/GGE) } \\
\hline Feedstock & 730.1 \\
\hline Pretreatment Chemicals & 33.5 \\
\hline A200 chemicals & 28.8 \\
\hline Hexane Solvent + Cleanup & 5.9 \\
\hline Hydrogen & 16.2 \\
\hline Natural Gas(supplemental and drying) & 16.1 \\
\hline Remaining Raw Materials & 1.3 \\
\hline Waste Streams & 0.0 \\
\hline Coproduct Credits & 0.0 \\
\hline Other Credits (recycled nutrients, etc.) & -64.3 \\
\hline Electricity(imported/exported) & -20.5 \\
\hline Catalyst & 10.1 \\
\hline Fixed Costs & 42.1 \\
\hline Capital Depreciation & 36.1 \\
\hline Average Income Tax & 11.5 \\
\hline Average Return on Investment & 103.0 \\
\hline \multicolumn{2}{|c|}{ Manufacturing Costs $(\$ / y r)$} \\
\hline Feedstock & $\$ 76,800,000$ \\
\hline Pretreatment Chemicals & $\$ 3,500,000$ \\
\hline A200 chemicals & $\$ 3,000,000$ \\
\hline Hexane Solvent + Cleanup & $\$ 600,000$ \\
\hline Hydrogen & $\$ 1,700,000$ \\
\hline Natural Gas(supplemental and drying) & $\$ 1,700,000$ \\
\hline Remaining Raw Materials & $\$ 3,200,000$ \\
\hline Waste Streams & $\$ 0$ \\
\hline Coproduct Credits & $\$ 0$ \\
\hline Other Credits (recycled nutrients, etc.) & $-\$ 6,800,000$ \\
\hline Electricity(imported/exported) & $-\$ 2,200,000$ \\
\hline Catalyst & $\$ 1,100,000$ \\
\hline Fixed Costs & $\$ 4,400,000$ \\
\hline Capital Depreciation & $\$ 3,800,000$ \\
\hline Average Income Tax & $\$ 1,200,000$ \\
\hline Average Return on Investment & $\$ 10,800,000$ \\
\hline
\end{tabular}




\section{Appendix A2: TEA Summary Sheet for Base Case CAP SOT Benchmark Model: BDO Case (FA Evaporation MBSP Scenario, 2016- dollars)}

\section{Combined Algal Processing to Fuels and Bioproducts Process Engineering Analysis 2019 SOT for Biomass Based on Florida Algae Evaporation and BDO Production}

Cost Year Basis:
MFSP (Gasoline Equivalent Basis):
Contributions: $r \begin{array}{r}\text { Feedstock } \\ \text { Conversion }\end{array}$
Total Fuel Production (RDB + Naphtha + Ethanol):
RDB Production:
Naphtha Production:
Total Fuel Yield ( RDB + Naphtha + Ethanol:
Feedstock Cost:
Internal Rate of Return:
Equity Percent of total Investment:

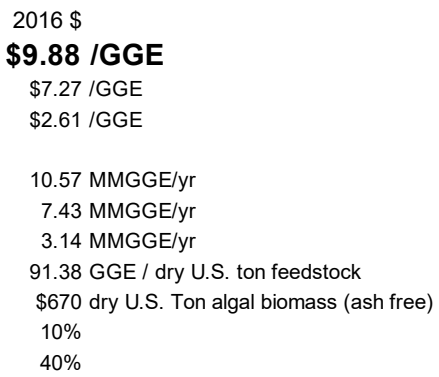

Capital Costs

\begin{tabular}{|c|c|}
\hline A100: Pretreatment and Conditioning & $\$ 23,500,000$ \\
\hline A200.23-BDO: 2,3-BDO Fermentation and Upgrading & $\$ 22,000,000$ \\
\hline A300: Lipid Separation and Co-products Fermentation and Upgrad & $\$ 11,900,000$ \\
\hline A400: Product Purification and Upgrading & $\$ 5,900,000$ \\
\hline A500: Protein/Residual Processing & $\$ 3,400,000$ \\
\hline A600: Combined Heat and Power & $\$ 4,200,000$ \\
\hline A700: Utilities \& Storage & $\$ 3,000,000$ \\
\hline Total Installed Equipment Cost & $\$ 73,900,000$ \\
\hline Added Direct + Indirect Costs & $\$ 70,500,000$ \\
\hline$(\%$ of $\mathrm{TCl})$ & $48.82 \%$ \\
\hline Total Capital Investment (TCl) & $\$ 144,400,000$ \\
\hline Installed Equiptment Cost/Annual GGE & $\$ 6.99$ \\
\hline Total Capital Investment/Annual GGE & $\$ 13.66$ \\
\hline Loan Rate & $8 \%$ \\
\hline Term(years) & 10 \\
\hline Capital Charge Factor (Computed) & 0.130 \\
\hline \multicolumn{2}{|l|}{ Carbon Retention Efficiencies: } \\
\hline Total Carbon Efficiency to Fuel Products & $46.3 \%$ \\
\hline \multicolumn{2}{|l|}{ (Fuel C/Biomass C) } \\
\hline RDB (RDB C/Biomass C) & $32.8 \%$ \\
\hline Naphtha (Naphtha C/Biomass C) & $13.5 \%$ \\
\hline \multicolumn{2}{|l|}{ Fuel Yields } \\
\hline Current RDB Production (U.S. ton/yr) & 22,865 \\
\hline Current Naphtha Production (U.S. ton/yr) & 9,578 \\
\hline
\end{tabular}

\begin{tabular}{lr}
\multicolumn{2}{c}{ Manufacturing Costs (cents/GGE) } \\
\hline Feedstock & 726.9 \\
Pretreatment Chemicals & 33.3 \\
A200 chemicals & 15.5 \\
Hexane Solvent + Cleanup & 11.6 \\
Hydrogen & 15.0 \\
Natural Gas(supplemental and drying) & 7.2 \\
Remaining Raw Materials & 1.8 \\
Waste Streams & 0.0 \\
Coproduct Credits & 0.0 \\
Other Credits (recycled nutrients, etc.) & -53.9 \\
Electricity(imported/exported) & -3.0 \\
Catalyst & 4.6 \\
Fixed Costs & 52.4 \\
Capital Depreciation & 42.6 \\
Average Income Tax & 13.5 \\
Average Return on Investment & 120.7 \\
& \\
& \multicolumn{1}{c}{ Manufacturing Costs (\$/yr) } \\
\hline Feedstock & $\$ 5,700,000$ \\
Pretreatment Chemicals & $\$ 300,000$ \\
A200 chemicals & $\$ 500,000$ \\
Hexane Solvent + Cleanup & $\$ 5,500,000$ \\
Hydrogen & $\$ 4,500,000$ \\
Natural Gas(supplemental and drying) & $\$ 1,400,000$ \\
Remaining Raw Materials & $\$ 12,800,000$ \\
Waste Streams & \\
Coproduct Credits & $\$ 1,500,000$ \\
Other Credits (recycled nutrients, etc.) & $\$ 1,600,000$ \\
Electricity(imported/exported) & $\$ 1,200,000$ \\
Catalyst & $\$ 1,600,000$ \\
Fixed Costs & $\$ 800,000$ \\
Capital Depreciation & $\$ 200,000$ \\
Average Income Tax & $\$ 0$ \\
Average Return on Investment & \\
& \\
& \\
&
\end{tabular}




\section{Appendix B: Life-Cycle Inventory (LCI) for 2019 CAP SOT Models}

Acids Case: SOT input and output inventory data for the modeled CAP process. (Note: Hourly rates shown below are based on annual averages over all modeled seasons.)

\begin{tabular}{|l|c|}
\hline Products (kg/hr) & \\
Diesel & 2189 \\
Naphtha & 1516 \\
Power Exported to Grid, kW & 4764 \\
\hline Resource Consumption (kg/hr) & \\
Feedstock (AFDW basis) & 13246 \\
Power, KW & 0 \\
Pretreatment Resource Consumption (kg/hr) & \\
Sulfuric-Acid (93\% pure) & 1152 \\
Ammonia & 372 \\
Carboxylic Acid Conversion Resource Consumption (kg/hr) & \\
Corn Steep Liquor & 699 \\
DAP & 74 \\
Membrane Flocculant & 74 \\
Lipid extraction and Conversion to Fuels Resource Consumption (kg/hr) & \\
Hexane Requirement & 9 \\
Ethanol Requirement & 29 \\
Hydrogen & 134 \\
Other Resource Consumption (kg/hr) & \\
Supplemental Natural Gas & 868 \\
Process Water & 51456 \\
Hydrotreating catalyst (5\% Pd/C) & 0 \\
Catalyst Ketonization (ZrO2) & 0 \\
Condensation Catalyst (Niobic Acid) & 0 \\
\hline Output Streams (kg/hr) & \\
AD Digestate cake (dry basis total flow) & \\
AD Digestate cake bioavailable N & \\
AD effluent NH3 & 3309 \\
AD effluent DAP & 18 \\
Recycle water excluding N/P nutrients & 188 \\
Air Emissions (kg/hr) & 95 \\
Water (H2O) & 92682 \\
Acetic Acid & 10456 \\
Oxygen & 0 \\
NO & 21527 \\
N2 & 105 \\
NO2 & 3173 \\
CO2 (Biogenic) & 2385 \\
CO2 (Fossil) & \\
SO2 & \\
H2 & \\
Biomass Loss from Storage (kg/hr) & \\
Algae biomass loss from wet storage & \\
\hline
\end{tabular}


BDO Case: SOT input and output inventory data for the modeled CAP process. (Note: Hourly rates shown below are based on annual averages over all modeled seasons.)

\begin{tabular}{|c|c|}
\hline $\begin{array}{l}\text { Products (kg/hr) } \\
\text { Diesel } \\
\text { Naphtha } \\
\text { Power Exported to Grid, kW }\end{array}$ & $\begin{array}{c}2619 \\
1097 \\
688\end{array}$ \\
\hline Resource Consumption (kg/hr) & \\
\hline Feedstock (AFDW basis) & 13246 \\
\hline Power Purchased, kW & 0 \\
\hline Pretreatment Resource Consumption $(\mathrm{kg} / \mathrm{hr})$ & \\
\hline Sulfuric-Acid (93\% pure) & 1152 \\
\hline Ammonia & 372 \\
\hline 2,3-BDO Conversion Resource Consumption ( $\mathrm{kg} / \mathrm{hr})$ & \\
\hline Corn Steep Liquor & 81 \\
\hline DAP & 10 \\
\hline Hydrogen & 10 \\
\hline Membrane Flocculant & 74 \\
\hline Lipid extraction and Conversion to Fuels Resource Consumption & \\
\hline Hexane Requirement & 69 \\
\hline Ethanol & 29 \\
\hline Hydrogen & 125 \\
\hline Other Resource Consumption ( $\mathrm{kg} / \mathrm{hr})$ & \\
\hline Supplemental Natural Gas & 394 \\
\hline Process Water & 69329 \\
\hline Hydrotreating catalyst $(5 \% \mathrm{Pd} / \mathrm{C})$ & 0 \\
\hline Dehydration catalyst Copper based (Cu/SiO2-ZrO2 or Cu/zeolite) & 0 \\
\hline Oligomerization catalyst (Amberlyst-36 resin) & 0 \\
\hline Output Streams, kg/hr & \\
\hline AD Digestate cake (dry basis total flow) & 3313 \\
\hline AD Digestate cake bioavailable $\mathrm{N}$ & 17 \\
\hline AD effluent $\mathrm{NH} 3$ & 178 \\
\hline$A D$ effluent $D A P$ & 61 \\
\hline recycle water excluding N/P nutrients & 94481 \\
\hline Air Emissions, kg/hr & \\
\hline Water $(\mathrm{H} 2 \mathrm{O})$ & 26465 \\
\hline Acetic Acid & 0 \\
\hline Oxygen & 20985 \\
\hline NO & 83 \\
\hline N2 & 98064 \\
\hline NO2 & 2 \\
\hline CO2 (Biogenic) & 8337 \\
\hline CO2 (Fossil) & 1266 \\
\hline SO2 & 53 \\
\hline $\mathrm{H} 2$ & 10 \\
\hline Biomass Loss from Storage, $\mathrm{kg} / \mathrm{hr}$ & \\
\hline Algae biomass loss from wet storage & 756 \\
\hline
\end{tabular}

